Document downloaded from:

http://hdl.handle.net/10251/147683

This paper must be cited as:

Primo Arnau, AM.; Franconetti, A.; Magureanu, M.; Mandache, NB.; Bucur, C.; Rizescu, C.; Cojocaru, B.... (2018). Engineering active sites on reduced graphene oxide by hydrogen plasma irradiation: mimicking bifunctional metal/supported catalysts in hydrogenation reactions. Green Chemistry. 20(11):2611-2623. https://doi.org/10.1039/c7gc03397d

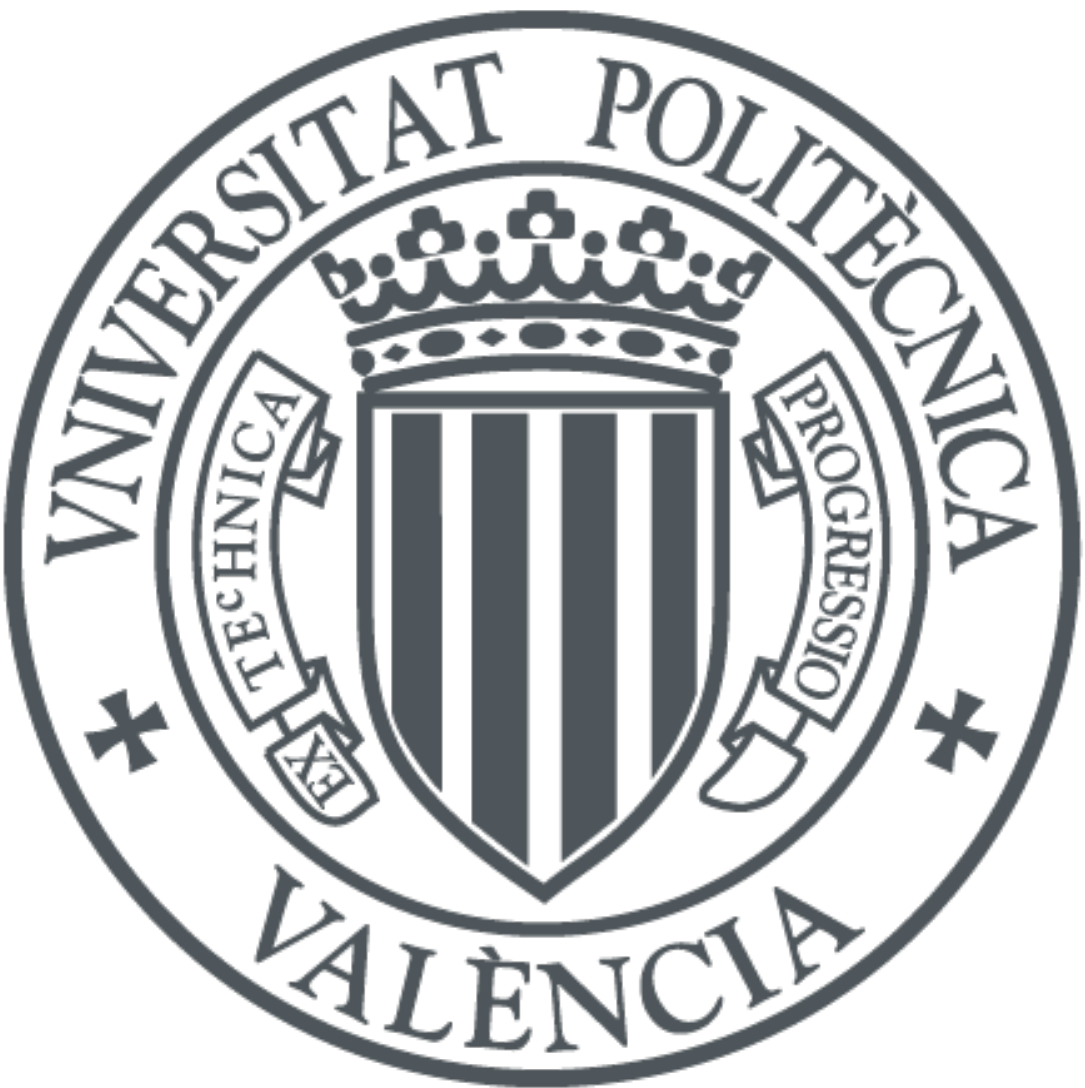

The final publication is available at

https://doi.org/10.1039/c7gc03397d

Copyright The Royal Society of Chemistry

Additional Information 


\title{
Engineering active sites on reduced graphene oxide by hydrogen plasma irradiation: Mimicking bifunctional metal/supported catalysts in hydrogenation reactions.
}

\author{
Ana Primo, ${ }^{1}$ Antonio Franconetti, ${ }^{2}$ Monica Magureanu, ${ }^{3}$ Nicolae Bogdan Mandache ${ }^{3}$, Cristina \\ Bucur, ${ }^{4}$ Cristina Rizescu, ${ }^{5}$ Bogdan Cojocaru, ${ }^{5}$ Vasile I. Parvulescu, ${ }^{5}$ Hermenegildo Garcia ${ }^{1}$ \\ ${ }^{1}$ Instituto Universitario de Tecnología Química, Universitat Politècnica de València-Consejo \\ Superior de Investigaciones Científicas, Avenida de los Naranjos s/n, 46022 Valencia, Spain \\ ${ }^{2}$ Departament de Química, Universitat Autònoma de Barcelona, 08193 Cerdanyola del Vallès, Spain \\ ${ }^{3}$ Department of Plasma Physics and Nuclear Fusion, National Institute for Lasers, Plasma and \\ Radiation Physics, 077125 Magurele, Romania \\ ${ }^{4}$ National Institute of Materials Physics, Atomistilor 105b, 077125 Magurele-Ilfov, Romania \\ ${ }^{5}$ Department of Organic Chemistry, Biochemistry and Catalysis, Faculty of Chemistry, University \\ of Bucharest, Bdul Regina Elisabeta, 4-12, Bucharest 030016, Romania;
} vasile.parvulescu@chimie.unibuc.ro

KEYWORDS: graphene, hydrogen plasma irradiation, hydrogenation reactions, carbocatalysis

\section{ABSTRACT}

$\mathrm{H}_{2}$ plasma has been used to generate carbon vacancies on reduced graphene oxide to increase its catalytic activity as hydrogenation catalyst. A relationship between the power of the plasma treatment and the exposure time with the activity of the material was observed for $\mathrm{C}=\mathrm{C}$ double bond hydrogenation. The activity data in the case of 1-octene, showing skeletal isomerization besides hydrogenation, indicates that $\mathrm{H}_{2}$ plasma treatment can introduce hydrogenating and acid sites rendering a bifunctional catalyst that is reminiscent of the activity of noble metals supported on acid supports.

\section{INTRODUCTION}

The use of carbon-based materials as metal-free catalysts to replace noble or critical metal catalysts is of a great current interest and is attracting special attention since the last decade. ${ }^{1-4}$ For 
this purpose, graphenes are among the most widely used materials and have already been investigated as metal-free catalysts in a large range of reactions. ${ }^{5-7}$ Of current importance are the oxygen reduction reactions, ${ }^{8}$ the hydrogenation of nitro groups ${ }^{9-11}$ or the hydrogenation of alkenes and alkynes. ${ }^{12}$

One of the key issues in this area is the nature of the active sites involved in the reaction mechanism. ${ }^{6,13}$ Understanding the structure of the active sites can eventually lead to prepare modified graphenes containing a large density of these centers. There are examples in the literature showing that the catalytic activity of graphenes can be increased by functionalization of the sheet by several methods, such as radical reactions, cycloadditions, hydrogenation, oxidations, etc., resulting in an enlargement of the potential of this type of materials for their use as catalysts in a large variety of reactions ${ }^{14}$ or by creating carbon defects in the graphene matrix. ${ }^{15-18}$ Due to the suitable properties of graphenes and related materials, the control of the extent and nature of the functional groups by submitting graphenes to post-modification appear to be essential to achieve more active and stable graphene catalysts. ${ }^{14}$

Very recently hydrogen plasma treatment has been proposed as an attractive, scalable approach for functionalization and patterning of mono- and multilayer graphenes. ${ }^{19,20}$ This treatment generates $\mathrm{H}$ atoms and a mixture of ions $\left(\mathrm{H}^{+}, \mathrm{H}_{2}{ }^{+}\right.$, and $\left.\mathrm{H}_{3}{ }^{+}\right)$that are able to react with graphene. ${ }^{21} \mathrm{In}$ accordance to molecular dynamics simulations, the produced $\mathrm{H}$ species present in the plasma are unable to hydrogenate the graphene basal plane, ${ }^{22-26}$ but exposure to this plasma can lead to the generation of holes on the graphene basal plane or to a decrease in the lateral dimensions of the layer. ${ }^{21}$ Other calculations aimed at modeling defects on graphene have concluded that carbon vacancies and holes should indeed play an important role in modulating the electronic properties of graphene and also in the enhancement of its chemical reactivity. ${ }^{27}$ Calculations based on models of these open-shell electronic structures simulating carbon vacancies on graphene have led to the conclusion that the reactivity of a hydrogen atom with the graphene sheet is significantly increased in carbon vacancies, suggesting that the creation of these type of defects should be positive to boost the catalytic activity of graphene for hydrogenation reactions.

Our previous studies have shown that defective graphenes exhibit catalytic activity to promote hydrogenation of C-C multiple bonds and nitro groups, ${ }^{11,12}$ but these materials were still much less efficient than transition metals and, therefore, it is crucial to find ways to improve further their activity as metal-free catalysts. ${ }^{13}$ Measurements of the catalytic activity of a series of graphenes for the fundamental isotopic H-D exchange process, combined with theoretical calculations have led to predict that one atom carbon vacancy on graphene can act as catalytic center in this process. ${ }^{28}$

In view of the current state of the art, the present manuscript reports the remarkable enhancement of the catalytic activity of a reduced graphene oxide (RGO) sample upon modification by hydrogen plasma treatment, correlating the extent of the graphene sheet exposure with their 
performance as catalyst for alkene hydrogenation. Experimental data have been rationalized by quantum mechanical calculations on models showing that vacancies of one or two carbon atoms should be interact strongly with molecular hydrogen, lending support to the existence of an optimal hydrogen plasma treatment to produce graphene sheets with the highest activity.

\section{EXPERIMENTAL}

The RGO sample used in the present study was obtained by Hummers-Offeman oxidation of graphite, subsequent exfoliation by sonication and hydrothermal reduction, following reported procedures. ${ }^{29}$

\section{Plasma treatment of graphenes}

The RGO sample was treated in a d.c. glow discharge in hydrogen. A cylindrical plasma reactor made of glass (inner diameter $65 \mathrm{~mm}$ ) with two planar electrodes (diameter $40 \mathrm{~mm}$ ) placed on the axis of the reactor was used (see Scheme S1). The distance between electrodes was $45 \mathrm{~mm}$. The reactor chamber was evacuated to a pressure of $3 \times 10^{-3}$ mbar, then, hydrogen was continuously flushed at a flow rate of $5 \mathrm{~mL} \times \mathrm{min}^{-1}$. The resulting working pressure was 0.1 mbar. Negative d.c. voltage was applied on one of the electrodes, while the other electrode was grounded. The discharge voltage was measured using a voltage probe (Tektronix P6015A) connected to an oscilloscope. Experiments were performed for discharge voltages in the range 500-800 V. The corresponding discharge power was between $0.4 \mathrm{~W}$ and $2 \mathrm{~W}$. The material was placed in the negative glow and the treatment time was varied from 15 to $60 \mathrm{~min}$.

Samples of graphene submitted to treatments at different powers were prepared. Table 1 lists the samples prepared in the present study in where the fist number corresponds to the discharge power and the second one to the treatment time.

Table 1. Samples prepared in the present study and relevant parameters of the plasma treatment.

\begin{tabular}{lccc}
\hline Sample & Discharge voltage (V) & Discharge power (W) & Treatment time (min) \\
\hline G0.4/60 & 500 & 0.4 & 60 \\
G1.1/15 & 660 & 1.1 & 15 \\
G1.1/30 & 660 & 1.1 & 30 \\
G1.1/60 & 660 & 1.1 & 60 \\
G2/60 & 800 & 2.0 & 60 \\
\hline
\end{tabular}




\section{Characterization of the materials}

Raman spectra were acquired in the extended spectral region from 150 to $4000 \mathrm{~cm}^{-1}$ using a Horiba JobinYvon - Labram HR UV-Visible-NIR Raman Microscope Spectrophotometer, exciting with a laser at $633 \mathrm{~nm}$. Diffuse Reflectance Fourier Transform Infrared (DRIFT) spectra were measured with a Thermo Electron Nicolet 4700 FTIR spectrophotometer adapted with a Smart Accessory for diffuse reflectance measurement. The IR spectra were scanned in the region of 4000$400 \mathrm{~cm}^{-1}$ at the resolution of $4 \mathrm{~cm}^{-1}$. The final spectra were an average of 400 scans.

Powder X-ray diffraction (XRD) patterns were recorded on a Schimadzu XRD-7000 diffractometer using $\mathrm{Cu} K \alpha$ radiation $(\lambda=1.5418 \AA, 40 \mathrm{kV}, 40 \mathrm{~mA})$ in the $5-90$ degrees $2 \Theta$ range.

Pulse chemisorption measurements were performed by an AutoChem II 2920 station from Micromeritics. The catalyst samples, placed in a U-shaped quartz reactor with an inner diameter of $0.5 \mathrm{~cm}$, were pretreated under He at $100{ }^{\circ} \mathrm{C}$ for $1 \mathrm{~h}$. Then, the samples were cooled down to RT under a helium flow of $50 \mathrm{ml} \mathrm{min}^{-1}$. Pulses of $\mathrm{H}_{2}\left(5 \% \mathrm{H}_{2}\right.$ in $\left.\mathrm{He}\right)$ were sent to the sample, until surface saturation was reached. The amount of adsorbed molecules was obtained by using a calibration plot. The desorption experiments were carried out using the same station. The $\mathrm{H}_{2}$ desorption experiments were carried out immediately after chemisorption by heating the sample at a constant heating rate $\left(10^{\circ} \mathrm{C} \times \mathrm{min}^{-1}\right)$ in a flow of helium till $400{ }^{\circ} \mathrm{C}$. $\mathrm{NH}_{3}$-TPD measurements were carried out on the same equipment. Before $\mathrm{NH}_{3}$ adsorption, fresh samples were heated to $120{ }^{\circ} \mathrm{C}\left(20{ }^{\circ} \mathrm{C} \mathrm{min}-1\right)$ in $30 \mathrm{~mL}$ helium flow. Subsequently, the samples were cooled down to RT also under helium flow. $\mathrm{NH}_{3}$ adsorption was performed under ambient conditions for $120 \mathrm{~min}$ in a flow of $10 \% \mathrm{NH}_{3}$ in helium $\left(30 \mathrm{~mL} \times \mathrm{min}^{-1}\right)$. Then, the samples were purged with helium to desorb weakly physisorbed ammonia. Subsequently, thermal desorption of $\mathrm{NH}_{3}$ was carried out heating at a constant rate $\left(10^{\circ} \mathrm{C} \times \mathrm{min}^{-1}\right)$ in helium flow till $400^{\circ} \mathrm{C}$.

TEM images were recorded in a JEOL JEM 2100F under accelerating voltage of $200 \mathrm{kV}$. Samples were prepared by applying one drop of the suspended material in ethanol onto a carboncoated copper TEM grid, and allowing them to dry at room temperature. XPS measurements were performed at normal angle emission in a Specs set up, using $\mathrm{Al} \mathrm{K \alpha}$ monochromated radiation (hv = $1486.7 \mathrm{eV})$ of an X-ray gun, operating with $300 \mathrm{~W}(12 \mathrm{kV} / 25 \mathrm{~mA})$ power. A flood gun with electron acceleration at $1 \mathrm{eV}$ and electron current of $100 \mu \mathrm{A}$ was used in order to avoid charging effects. The energy of photo ejected electrons are measured using a Phoibos 150 analyzer, operating with pass energy of $30 \mathrm{eV}$. The XP spectra were fitted using Voigt profiles combined with their primitive 
functions, for inelastic backgrounds. The Gaussian width of all lines and thresholds can be considered constant for each spectrum as they should not differ considerably from one spectrum to another, being always in the range of $2 \mathrm{eV}$. The spectra were collected in the energy range corresponding to $\mathrm{C} 1 \mathrm{~s}$ and O1s species.

\section{Catalytic tests for cyclohexene hydrogenation and 1-octene hydroisomerization}

The catalytic tests were carried out with suspended RGO and hydrogen plasma-treated RGO samples (Table 1). For comparison, a commercial zeolite Beta (PQ Industries, Si/Al ratio of 18) and physical mixtures of RGO and zeolite Beta have been investigated as well. The physical mixtures were prepared by 30 min sonication of RGO/zeolite Beta mixtures in ratio 1:1.

The catalytic tests were performed under stirring conditions in a batch autoclave from Hell using $10 \mathrm{mg}$ of catalyst and $3 \mathrm{ml}$ of substrate. The experiments were carried out at $120{ }^{\circ} \mathrm{C}$ for cyclohexene ( $3 \mathrm{ml}$ ) and $80{ }^{\circ} \mathrm{C}$ for 1-octene (3 ml), under 30 bar $\mathrm{H}_{2}$ pressure, using $3 \mathrm{ml}$ of $n$-heptane as a solvent and reaction times in a range of $1.5-4 \mathrm{~h}$. All the investigated compounds were purchased from Sigma-Aldrich. Before pressurization, the autoclave was flushed several times with $\mathrm{H}_{2}$. The reactants and products were analyzed using a GC-MS apparatus (Thermo Electron Trace GC Ultra/Trace DSQ) equipped with a non-polar GC capillary column (TG-5SilMS, $30 \mathrm{~m} \times 0.25$ $\mathrm{mm} \times 0.25 \mu \mathrm{m}$ ) operated with He as carrier gas. Temperature profile was set to $2 \mathrm{~min}$ dwell at $60{ }^{\circ} \mathrm{C}$, $5{ }^{\circ} \mathrm{C} \times \min$ ramp up to $170{ }^{\circ} \mathrm{C}$, followed by a $5 \mathrm{~min}$ dwell. Mass spectra were recorded for positive ions and full scan mode in the range $\mathrm{m} / \mathrm{z}=50-300$.

\section{Computational details}

Theoretical calculations were carried out by means of the Gaussian 09 program. ${ }^{30}$ Geometry optimizations were performed at two different levels of theory and basis sets. Geometrical calculations were initially made using the PBE0 hybrid functional at 6-31G(d). A $4 \times 4$ graphene sheet terminated by $\mathrm{H}$ atoms containing one or two carbon vacancies in its structure was used as model for activation of a $\mathrm{H}_{2}$ molecule. For all optimizations, frequencies analyses were applied to characterize the graphene flakes as minimum, transition state or as metastable state. In addition, the role of different spin multiplicity (from singlet to triplet) on the graphene geometry as well as on the energy of the system was studied.

The formation energies $\left(E_{\mathrm{f}}\right.$, in $\left.\mathrm{eV}\right)$ of vacancies in graphene are defined as follows ${ }^{31}$ :

$$
E_{\mathrm{f}}=E_{\mathrm{d}}+n E_{\mathrm{c}}-E_{\mathrm{p}}
$$


In which $E_{\mathrm{d}}$ and $E_{\mathrm{p}}$ are the energies of optimized structures for defective and perfect graphenes, respectively. $E_{\mathrm{c}}$ is the energy for the removed carbon atom whereas $n$ is 1 or 2 depending on the number of removed atoms for building vacancies.

Moreover, adsorption energies (eV and $\mathrm{kcal} \mathrm{mol}^{-1}$ ) between defective graphenes and molecular hydrogen $\mathrm{H}_{2}$ at PBE0/6-31G(d) were calculated as follows:

$$
\Delta E_{\text {adsorption }}=E_{\text {complex }}-E_{\text {graphene }}-E_{\mathrm{H} 2}
$$

in which $E_{\text {complex }}$ is the corresponding energy of defective graphene $\cdots \mathrm{H}_{2}$ complexes where $E_{\text {graphene }}$ and $E_{\mathrm{H} 2}$ are the optimized energies for single defective graphenes and $\mathrm{H}_{2}$ molecule, respectively.

\section{RESULTS AND DISCUSSION}

\section{Characterization of hydrogen plasma treated graphenes}

Table 2, Figure $\mathrm{S} 1$ and Figure S2A compile the $\mathrm{H}_{2}$ chemisorption and desorption measurements for the hydrogen plasma-treated graphene samples under study. These measurements can serve to determine the adsorption capacity and strength of the interaction of the different samples with $\mathrm{H}_{2}$ as a function of the hydrogen plasma treatment. These values are relevant in the context of the use of these hydrogen plasma-treated graphenes as hydrogenation catalysts. As it can be seen in Table 2, plasma exposure of RGO enhanced $\mathrm{H}_{2}$-adsorption, increasing along the power and duration of the plasma treatment, there being an abrupt increase for long exposure times (60 min) and high powers $(1.1$ or $2.0 \mathrm{~W})$. However, the hydrogen desorption measurements up to $400{ }^{\circ} \mathrm{C}$ do not follow the same trend, those being a maximum for G1.1/30. These differences can be attributed to a spillover of hydrogen on the graphene sheet, becoming chemically bound for those graphene samples submitted to long plasma exposure times. Finally the chemisorbed hydrogen corresponding to the difference between adsorbed and desorbed amounts was recovered for temperatures higher that 450 ${ }^{\circ} \mathrm{C}$. Note that according to Table 2, light to moderate hydrogen plasma treatments increases equally the amount of sorbed and desorbed hydrogen indicating that under these conditions plasma treatment results almost exclusively on physisorbed hydrogen. In contrast, harsh plasma treatment results in a notable increase of chemisorbed $\mathrm{H}_{2}$ that is notably more strongly bound to graphene, indicating that other types of centers are created under these conditions. According to our theoretical calculations the differences in the chemisorbed and desorbed hydrogen can be an indication of the ratio between one carbon atom vacancy (ie strongly interacting $\mathrm{H}_{2}$ ) and double carbon vacancy (ie weaker interacting $\mathrm{H}_{2}$ ). Since one $\mathrm{H}_{2}$ molecule can occupy one vacancy, according to Table 2 and Figure $\mathrm{S} 1$ 
the population of one atom vacancies is increasing with the power and time of the plasma treatment. It can be calculated as the difference between the chemisorbed and desorbed hydrogen.

Table 2. Summary of $\mathrm{H}_{2}$ adsorption and desorption measurements for the samples under study.

\begin{tabular}{|c|c|c|}
\hline \multirow[t]{3}{*}{ Sample } & \multirow{3}{*}{$\begin{array}{c}\mathrm{H}_{2} \text { adsorption } \\
\text { Molecules } \times 10^{20} / \mathrm{g}\end{array}$} & \multirow{3}{*}{$\begin{array}{c}\mathrm{H}_{2} \text { desorption } \\
\text { Molecules } \times 10^{20} / \mathrm{g} \\
\text { up to } 400{ }^{\circ} \mathrm{C}\end{array}$} \\
\hline & & \\
\hline & & \\
\hline RGO & 7.63 & 4.27 \\
\hline G0.4/60 & 7.77 & 7.10 \\
\hline G1.1/15 & 10.06 & 8.49 \\
\hline G1.1/30 & 10.78 & 10.12 \\
\hline$\overline{\mathrm{G} 1.1 / 60}$ & 40.50 & 6.32 \\
\hline$\overline{\mathrm{G} 2 / 60}$ & 45.60 & 3.61 \\
\hline
\end{tabular}

TPD-NH$H_{3}$ measurements show clearly an increase of the number of moderate strength acidic sites along with the plasma power and irradiation time (figure S2B), except G1.1/30 which is the most acidic in the series.

Figure 1 presents the XRD patterns of RGO and the $\mathrm{H}_{2}$-plasma treated samples. All of these present the typical diffraction line of the graphitic stacking of reduced sheets at around $2 \Theta 24.5^{\circ}$. The layer spacing calculated with the aid of Bragg equation $(\lambda=2 \mathrm{~d} \sin (\Theta)$, where $\lambda$ is the wavelength of the X-ray beam, $\mathrm{d}$ the distance between the adjacent sheets or layers, and $\Theta$ the diffraction angle) corresponds $0.364,0.358,0.361,0.356,0.359$ and $0.358 \mathrm{~nm}$ for RGO, G0.4/60, G1.1/15, G1.1/30, G1.1/60, and G2/60, respectively, which is an evidence of the stability of RGO towards plasma treatment against delamination. The broadness of this line is associated to two factors: i) the small sheet size (1 $\mu \mathrm{m}$ and below) and, ii) a relatively short domain order or turbostratic arrangement of RGO stacked sheets. ${ }^{32}$ Beside this broad line, RGO presents two additional narrow and sharp, lessintense lines at $2 \Theta 21.4$ and $23.7^{\circ}$, respectively. These can be attributed to residual graphite and correspond to an interlayer space of 0.414 and $0.375 \mathrm{~nm}$, respectively. In addition, G1.1/15 and G1.1/30 present a broad line at about $2 \Theta 43.5^{\circ}$, assigned to the facet (100) of carbon with an interlayer spacing of $0.208 \mathrm{~nm}$ and associated with a partial reduction. 


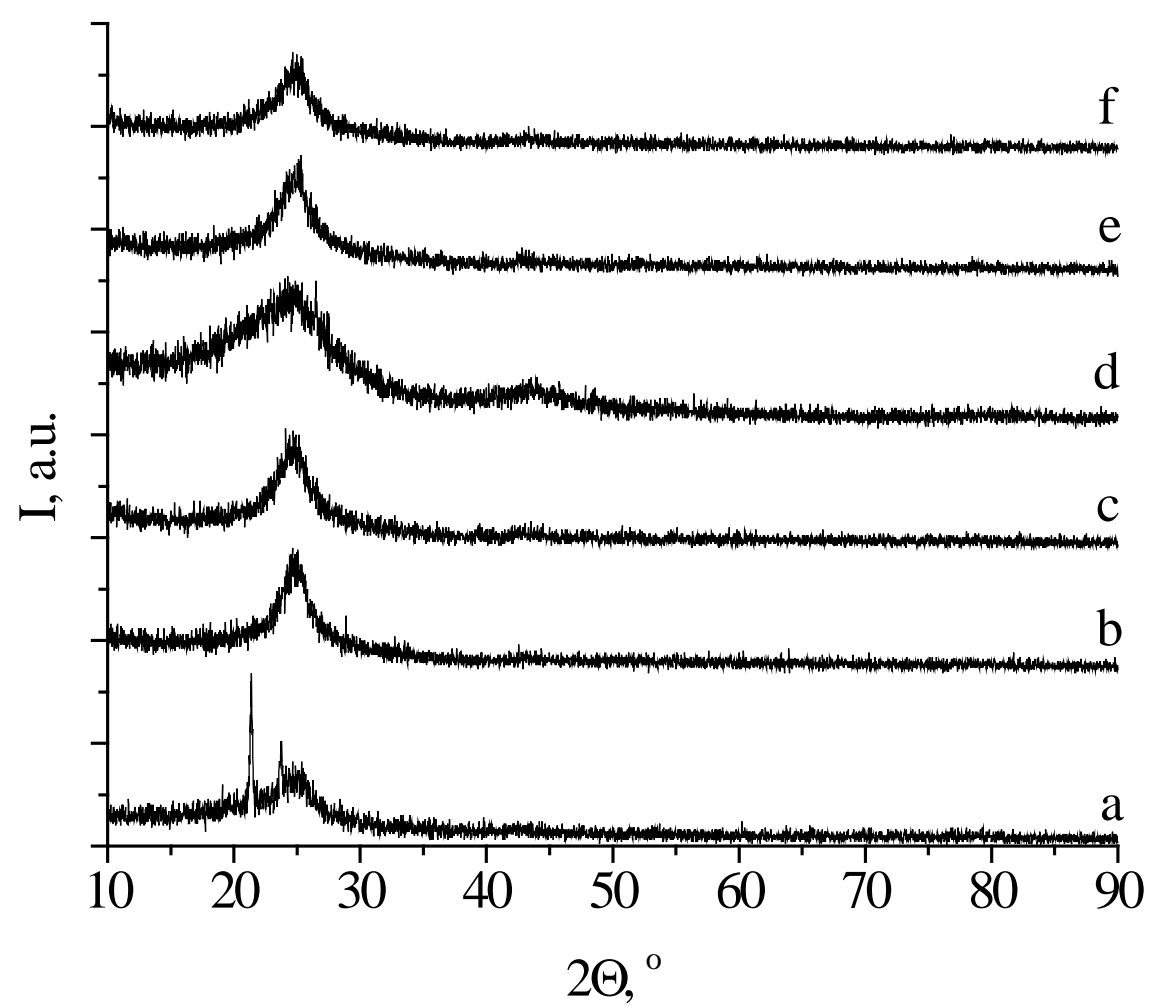

Figure 1. X-Ray diffractograms of a) RGO, b) G0.4/60, c) G1.1/15, d) G1.1/30, e) G1.1/60, f) $G 2 / 60$

Raman spectroscopy of graphenes is sensitive to defects, excess charge, strain or the atomic arrangement of the edges. The increase of the disorder in graphene parallels the $D / G$ intensity ratio. A larger density of defects creates a more elastic scattering (the as named regime of „low” defect density). An increase of the defect's density after a certain level results in a more amorphous carbon structure which attenuates the Raman peaks (the as named regime of "high" defect density). This corresponds to a decrease of the $\mathrm{D} / \mathrm{G}$ intensity ratio. ${ }^{33}$ On the other side, broader and overlapped $\mathrm{G}$ and $\mathrm{D}$ lines correspond to a more oxidized graphene oxide, while a high $\mathrm{D} / \mathrm{G}$ intensity ratio and the narrow lines indicate a decrease in the average size of the $\mathrm{sp}^{2}$ domains in a reduced $\mathrm{GO}^{34}$. The $\mathrm{D} / \mathrm{G}$ intensity ratio (Figure 2) increases in the following order G1.1/30 $<\mathrm{G} 1.1 / 60 \sim \mathrm{G} 2 / 60<\mathrm{G} 1.1 / 15<$ G0.4/60. A shift of the D band to higher wavenumbers can be observed for the G1.1/15, G1.1/30 and G1.1/60 samples. This is accompanied by a broadening of the $G$ and D bands (overlapping) which can be attributed to a higher disorder and correlates to XRD data showing a peculiar pattern for G1.1/15 and G1.1/30. These changes stress the importance of the irradiation time. 


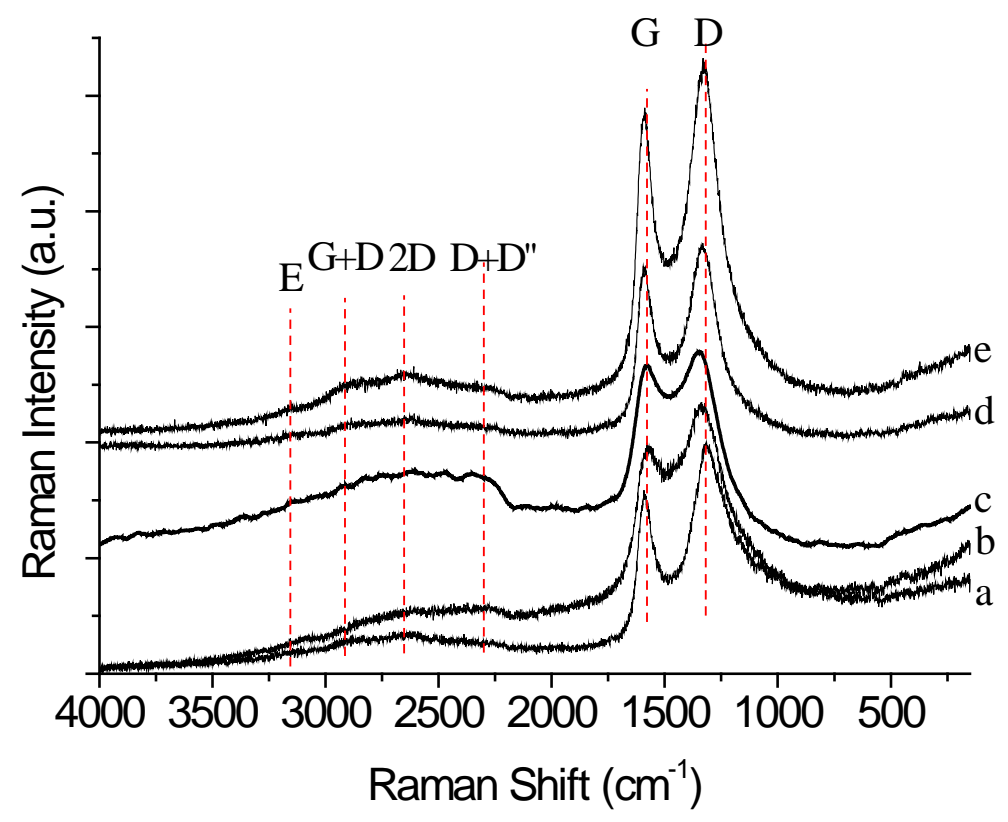

Figure 2. Raman spectra of a) G0.4/60, b) G1.1/15, c) G1.1/30, d) G1.1/60, e) G2/60

DRIFT spectroscopy was also used to determine any possible influence of the graphene sheet in the $\mathrm{H}_{2}$ chemisorption and desorption experiments, particularly the possible formation of $\mathrm{C}-\mathrm{H}$ bonds. The band associated with hydroxyl groups in the $3200-3500 \mathrm{~cm}^{-1}$ (range not shown) was absent in all the collected spectra. RGO and G0.4/60 present similar DRIFT spectra (Figure 3 A) although the intensity of the bands is much lower for RGO. The band at about $785 \mathrm{~cm}^{-1}$ can be attributed to C-O in ethers, ${ }^{35}$ while that at $1010-1090 \mathrm{~cm}^{-1}$ to $\mathrm{C}-\mathrm{O}$ in C-O-C epoxy, ${ }^{36} \mathrm{C}-\mathrm{OH}$ or $\mathrm{COOH},{ }^{35}$ the band at $1550 \mathrm{~cm}^{-1}$ is assigned to $\mathrm{C}=\mathrm{O}{ }^{37}$ or to in-plane vibrations of $\mathrm{sp}^{2}$-hybridized $\mathrm{C}=\mathrm{C},{ }^{35}$ while that at $1735 \mathrm{~cm}^{-1}$ to carboxyl groups.

Treating RGO at higher plasma power led to a modification of the samples which was reflected in the DRIFT spectra. The band at $785 \mathrm{~cm}^{-1}$ attributed to C-O shifted to $955 \mathrm{~cm}^{-1}$. The new bands at about 1080 and $1150 \mathrm{~cm}^{-1}$ are attributed to $\mathrm{COOH}$ groups, ${ }^{35}$ while that at $1385 \mathrm{~cm}^{-1}$ to organic carbonates. The new bands at 2887 and $2979 \mathrm{~cm}^{-1}$ confirm the aromatic structure of graphene. ${ }^{38}$

The exposure to $\mathrm{H}_{2}$ does not change the band positions (Figure $3 \mathrm{~B}$ ). Only a slight increase of the intensity was observed after the samples were exposed to $\mathrm{H}_{2}$. This provides a nice evidence of the stability of these hydrogen plasma irradiated RGO samples under the conditions required in the hydrogenation reaction. 

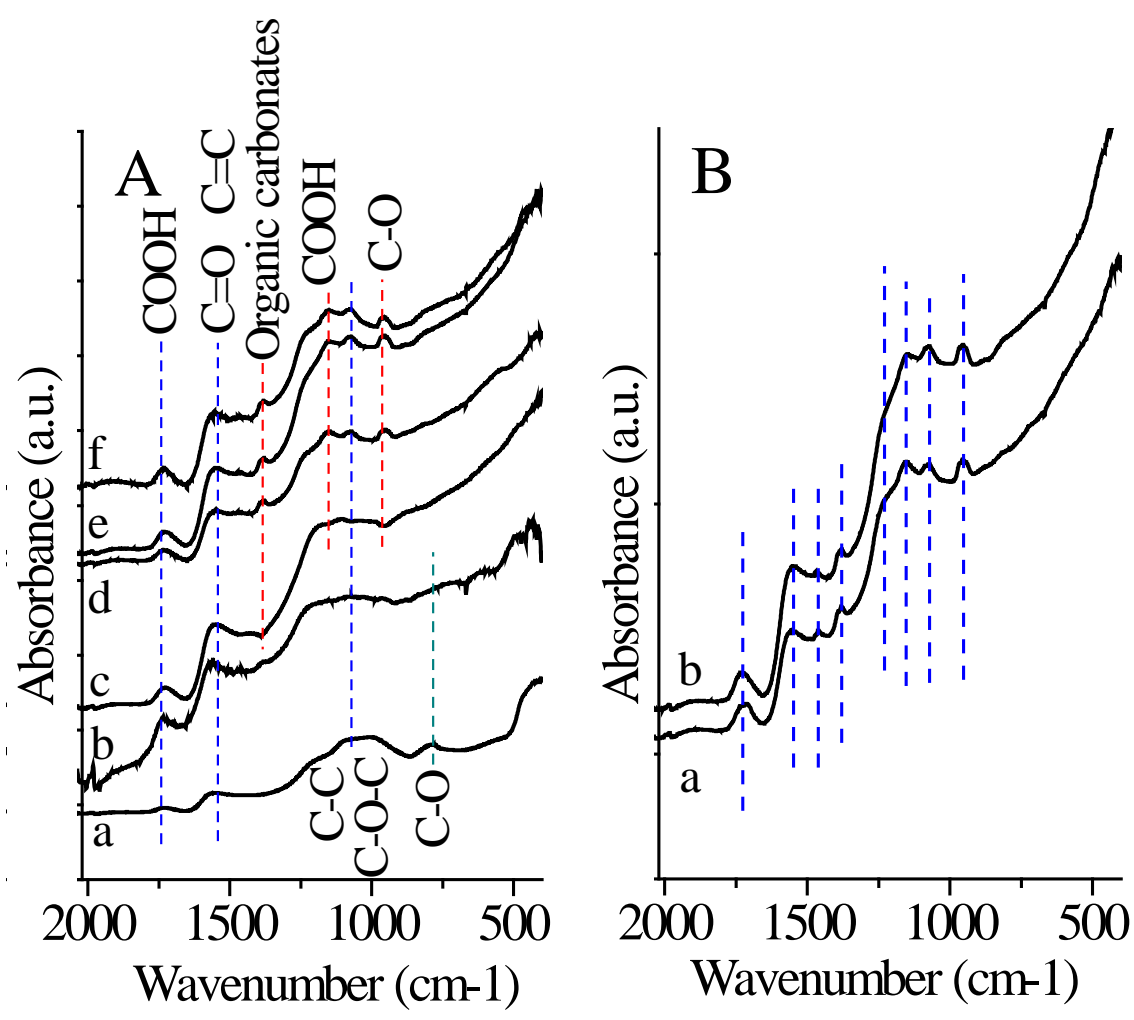

Figure 3. A. DRIFT spectra of the samples: a) RGO, b) G0.4/60, c) G1.1/15, d) G1.1/30, e) G1.1/60, f) G2/60 (bands in blue were detected in all the samples; those in red for the high energy irradiated samples; and those in green for RGO and G0.4/60); B. DRIFT spectra of G1.1/60 a) fresh and b) after TPD- $\mathrm{H}_{2}$ experiments

Figures 4 and 5 depict the XP spectra in the binding energy range corresponding to the $\mathrm{C} 1 \mathrm{~s}$ and O1s levels. The deconvolution of the bands assigned to these levels revealed the presence of the multiple functionalities ( $\mathrm{C}-\mathrm{C}, \mathrm{C}=\mathrm{C}, \mathrm{C}-\mathrm{O}, \mathrm{C}-\mathrm{OH}$ and $\mathrm{C}=\mathrm{O}$ ). Their intensity in the separate spectra of C1s and O1s correlates very well. Also, the intensity of the deconvoluted bands was directly dependent on the $\mathrm{H}_{2}$-plasma irradiation conditions (see also Table $\mathrm{S} 1$ ). Thus, the $\mathrm{H}_{2}$ plasma irradiation treatment increases the population of the $\mathrm{OH}$ groups that is also described by the $\mathrm{O} / \mathrm{C}$ ratio (Figure $\mathrm{S} 1$ ) and the $\mathrm{C}-\mathrm{O} / \mathrm{C}=\mathrm{O}$ ratio (Figure S2). These changes also correlate to the formation of defects. 

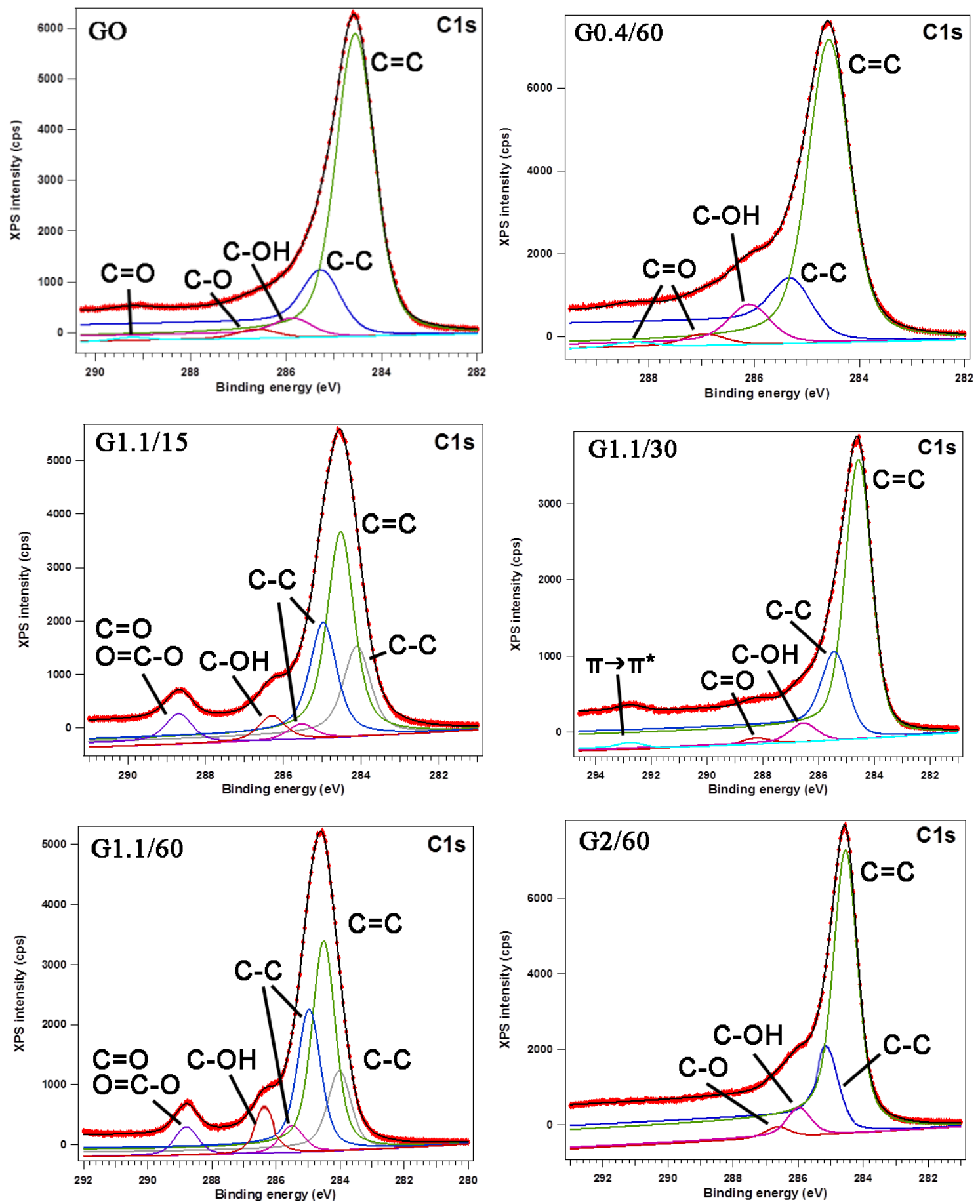

Figure 4. XP spectra of the $\mathrm{H}_{2}$-plasma treated samples in the region of the $\mathrm{C} 1 \mathrm{~s}$ level. 

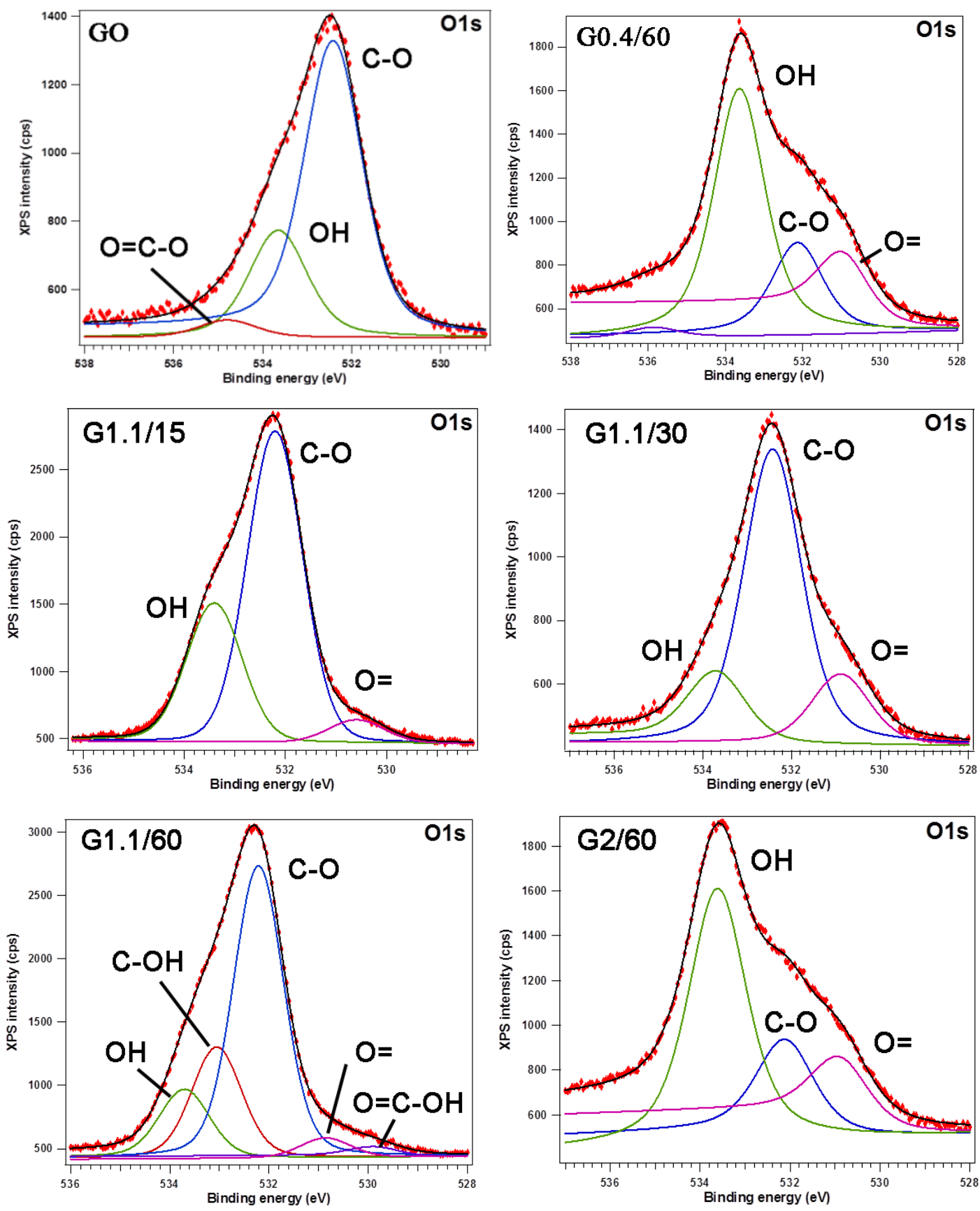

Figure 5. XP spectra of the $\mathrm{H}_{2}$-plasma treated samples in the region of the O1s level.

The expected effect of hydrogen-plasma treatment producing carbon vacancies and holes as reported in the literature ${ }^{18,21}$ was addressed by transmission electron microscopy (TEM) of the G2/60 that corresponds to the sample submitted to the highest plasma power for the longest time. In the literature it has been observed that plasma treatment can results in the generation of holes of about 15 nm diameters. No such holes were observed in the present case, even at the harsher conditions corresponding to G2/60. Thus, in our cases, the defects are more likely to consist in changes in the oxygenated functional groups and carbon vacancies that are more difficult to be seen by electron microscopy due to their much smaller size and the low contrast of light atoms. Figure 6 presents 
representative TEM images of this sample, showing that at the highest magnification the atom alignment exhibits a considerable density of white spots that can be attributed to atom vacancy in this sample. These subnanometric white spots observed at the highest resolution in Figure 6 are proposed to correspond to the defects generated by the $\mathrm{H}_{2}$ plasma treatment. Figure $\mathrm{S} 3$ in the supplementary information provides an additional series of TEM images corresponding to the samples G1.1/15, G1.1/60 and G2/60, where an increase in the density of the white spots on the graphene sheet attributed to defects can be seen.

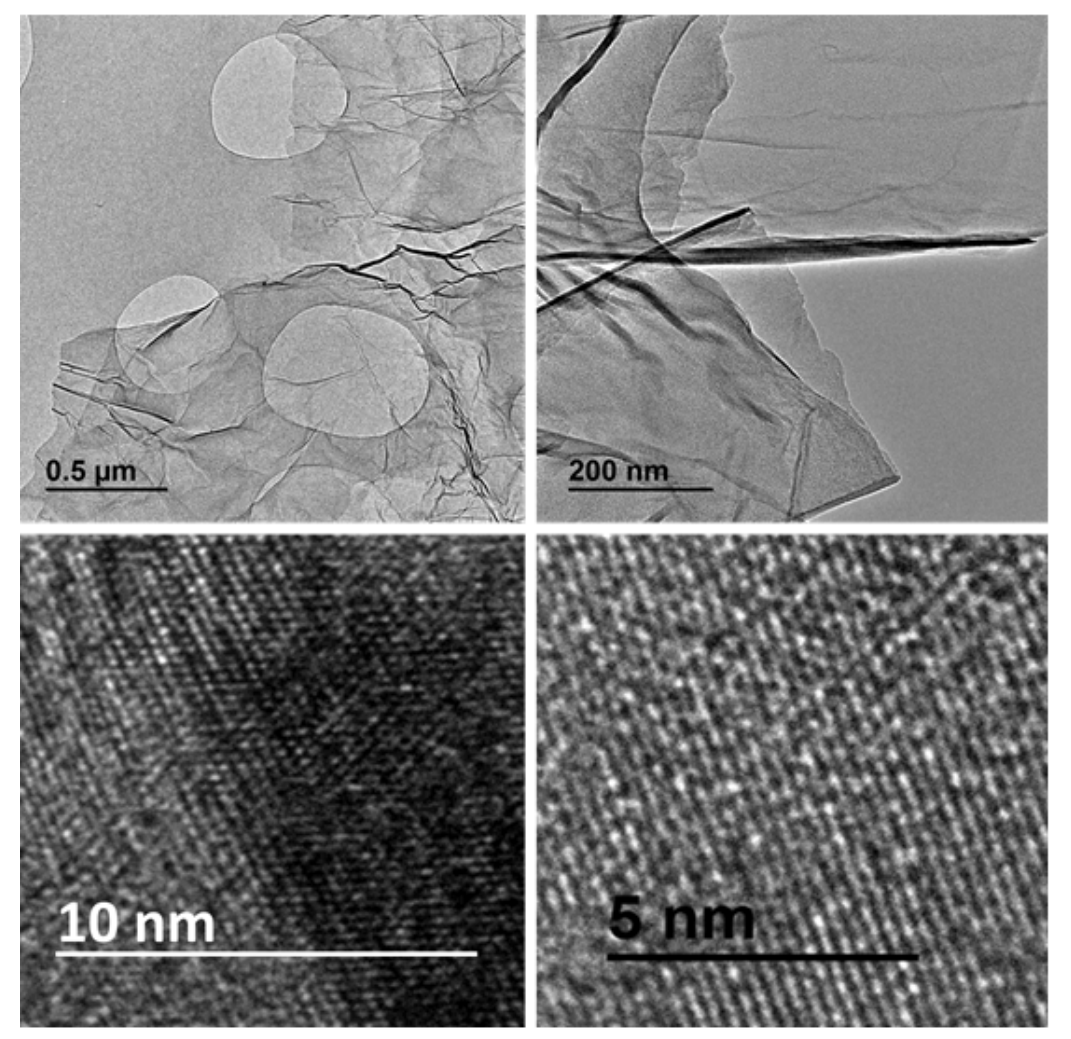

Figure 6. TEM images taken for G2/60 at different magnifications, showing the characteristic morphology of few layers graphene with a light contrast and the presence of wrinkles. At the highest magnification, the white spots in the lines corresponding to the hexagonal atom arrangement are proposed to be the defects consisting in carbon atom vacancies originated by hydrogen plasma treatment.

\section{Catalytic activity}

As commented in the introduction, the purpose of the present study is to show the possibility to increase the activity of graphenes as hydrogenation catalysts by generating defects on the sheet that can act as active sites to promote hydrogenations. ${ }^{13,28}$ 
The beneficial effect of $\mathrm{H}_{2}$-plasma irradiation on the activity as hydrogenation catalysts can be clearly seen in Figure 7, where the time conversion plots for the liquid-phase cyclohexene hydrogenation promoted by the various graphene samples under study are presented. As expected in view of the existing precedents, the treated graphene samples were able to promote cyclohexene hydrogenation to cyclohexane as the only product observed, ${ }^{11,12}$ increasing the catalytic activity along the power and duration of the plasma treatment.

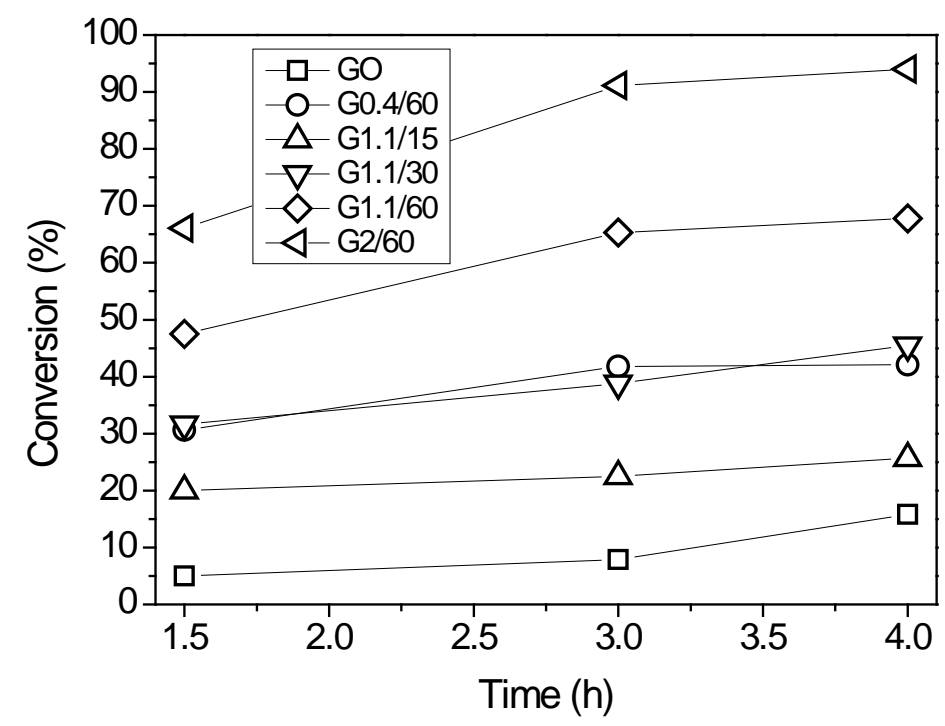

Figure 7. Time-conversion plots for hydrogenation of cyclohexene catalyzed by hydrogen plasma-treated graphene catalysts. Reaction conditions: cyclohexene ( $3 \mathrm{ml})$, n-heptane as solvent (3 ml), catalyst $10 \mathrm{mg}$, initial $\mathrm{H}_{2}$ pressure $30 \mathrm{bar}, 80^{\circ} \mathrm{C}$, magnetic stirring in autoclave.

Similar relative catalytic order as that commented for cyclohexene was also observed using 1-octene as substrate, although in this case the product distribution includes positional and skeletal isomers of 1-octene as well as octane, as indicated in Scheme 1. Thus, Figure 8 presents the timeconversion plots for 1-octene conversion, showing that the activity of the graphene catalysts increases with the power and time of $\mathrm{H}_{2}$-plasma irradiation. 

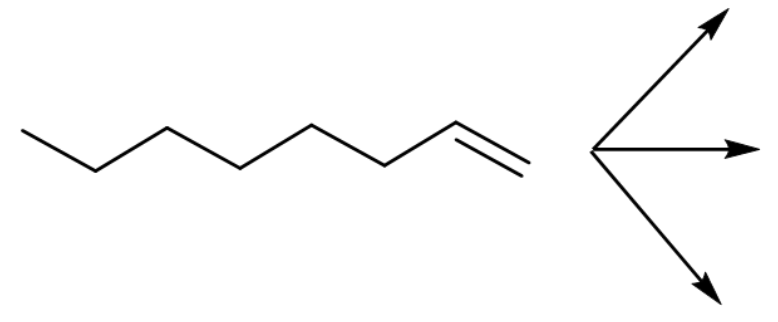

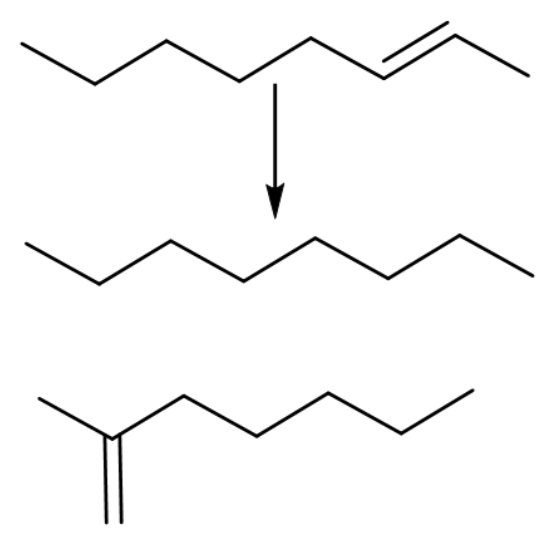

Scheme 1. Hydroisomeration and hydrogenation products formed from 1-octene.

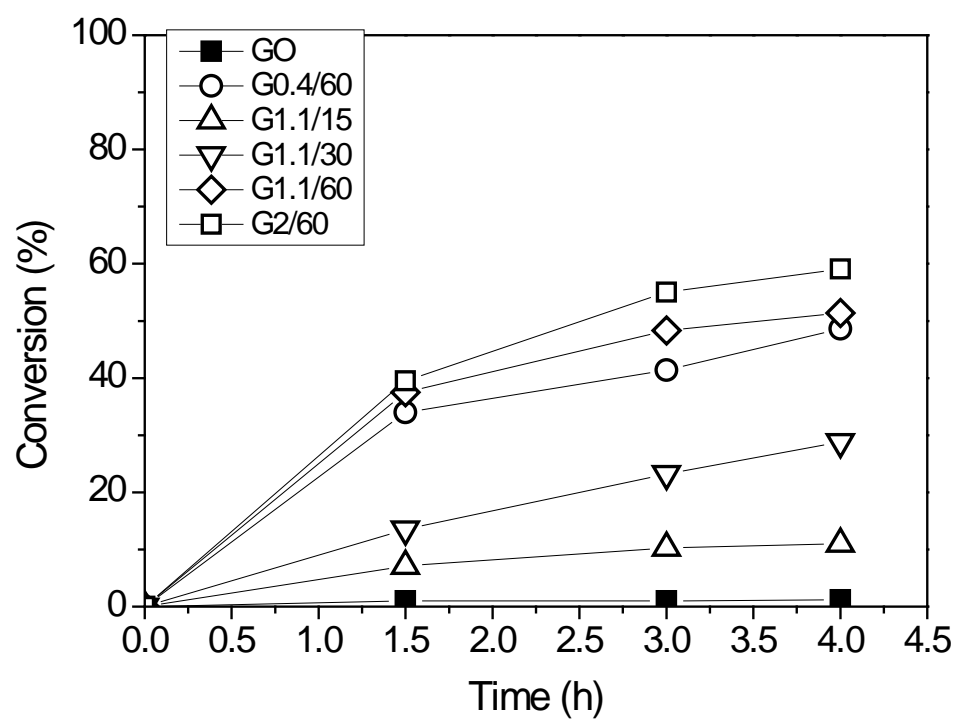

Figure 8. Time-conversion plots for 1-octene transformation under $\mathrm{H}_{2}$ catalyzed by hydrogen plasma-treated graphene catalysts. Reaction conditions: 1-octene ( $3 \mathrm{ml}), \mathrm{n}$-heptane as solvent (3 ml), catalyst $10 \mathrm{mg}$, initial $\mathrm{H}_{2}$ pressure $30 \mathrm{bar}, 120^{\circ} \mathrm{C}$, magnetic stirring in autoclave.

One difference between the activity data for cyclohexene and 1-octene is the negligible catalytic activity observed for the parent reduced graphene oxide in the 1-octene conversion. However, the most salient feature of 1-octene as substrate is that it allows a better understanding of the effect of the changes produced in reduced graphene oxide by plasma irradiation with hydrogen by analysis of the selectivity of the reaction, particularly from the appearance of skeletal isomer 2-methyl-1-heptene. Figure 9 presents product selectivity for the reaction of 1-octene as a function of the reaction time in the presence of the various graphene catalysts used in the present study. 


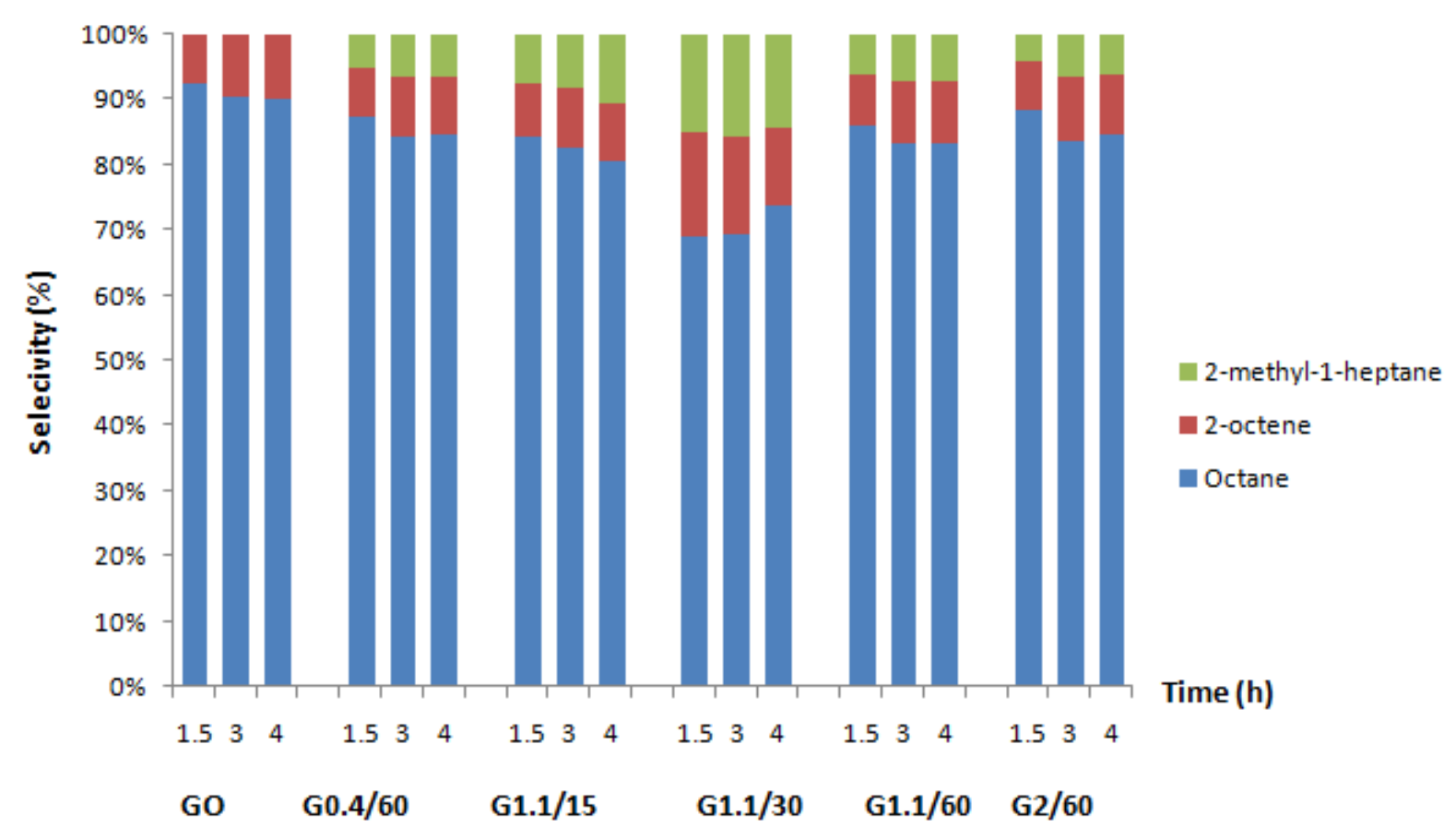

Figure 9. The variation of the selectivity to 2-octene, 2-methyl-1-heptene and octane using different graphene samples as catalyst as a function of the reaction time. Reaction conditions: 1-octene (3 ml), n-heptane as solvent ( $3 \mathrm{ml}$ ), catalyst $10 \mathrm{mg}$, initial $\mathrm{H}_{2}$ pressure $30 \mathrm{bar}, 120{ }^{\circ} \mathrm{C}$, magnetic stirring in autoclave.

While RGO merely produces hydrogenation of 1-octene to octane (Figure 5) and, in a lesser extent isomerization to 2-octene, the changes in the surface functionalities, including generation of mildly acidic $\mathrm{OH}$ groups, due to plasma irradiation, allowed skeletal isomerisation resulting in the formation of 2-methyl-1-heptene (Scheme 1) which is present in the rest of the graphene catalysts. It is well-established that the formation of this product requires a bifunctional acidic and hydrogenating catalyst and this process is typically observed, for instance, with catalysts containing noble metal nanoparticles supported on a solid acid. ${ }^{39,} 40$ Moreover, the selectivity towards 2-methyl-1-heptene reaches a maximum of $15.5 \%$ for the G1.1/30 sample. The total selectivity to the isomerization products on this G1.1/30 catalyst was about 31\%. By correlation to the $\mathrm{H}_{2}$ chemisorption, TPD- $\mathrm{H}_{2}$, XPS and DRIFT spectroscopic characterization, the behavior of G1.1/30 seems to correspond to an intermediate population of acidic groups and an intermediate level density of defects. This interpretation agrees with acidity characterization data for the various graphene samples under study determined by $\mathrm{NH}_{3}$ TPD that are provided in supporting information (Figure S4). $\mathrm{NH}_{3} \mathrm{TPD}$ measurements show that the acidity changes with the hydrogen plasma treatment and that the most acidic samples are those submitted to low energy plasma and short irradiation times, particularly, G1.1/30 and G1.1/15, decreasing as the time or the power increase further. These acidity data from 
$\mathrm{NH}_{3}$ TPD agree well with the assumption that the skeletal isomerization leading to 2-methyl-1heptane requires a balanced contribution of acidity and hydrogenating activity.

To further confirm the role of acidity in the skeletal hydroisomerization of 1-octene, the catalytic behavior of a zeolite Beta and the 1:1 physical mixture with RGO was also evaluated. The results are presented in Figures 10 and 11, which show the time-conversion plot for 1-octene and the product selectivity at three different reaction times for zeolite Beta, RGO and the 1:1 physical mixture. As can be seen in these Figures, due to its known acidity, Beta zeolite also afforded the skeletal hydroisomerization of 1-octene in similar extent as the irradiated G1.1/30 sample (compare selectivity data from Figures 9 and 10), while this product is not observed in the RGO test. Likewise, in terms of total isomerization activity the catalytic behavior of zeolite Beta was similar as that of the plasma irradiated G1.1/30 sample (ca 34\%), exhibiting a maximum selectivity to octane of $72 \%$ after $4 \mathrm{~h}$ reaction time. In other words, the combination of zeolite Beta and RGO results in a catalytic behavior similar to that of G1.1/30, supporting our assumption that the activity of G1.1/30 for the transformation of 1-octene can be rationalized as arising from the hydrogenating activity similar to RGO plus acidity that could be introduced alternatively by zeolite Beta.

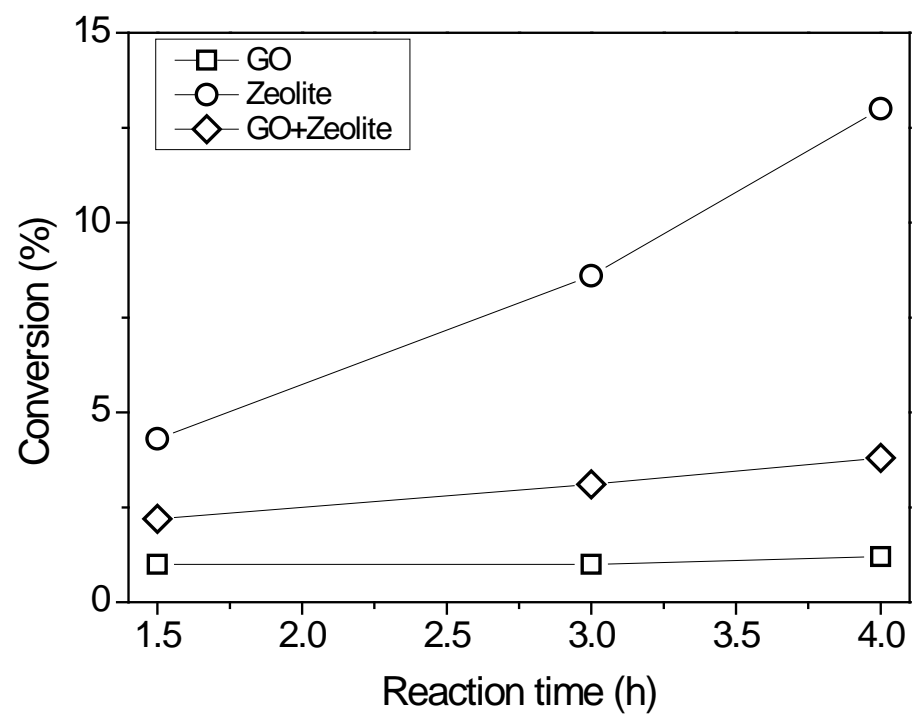

Figure 10. Time-conversion plot for the reaction of 1-octene with $\mathrm{H}_{2}$ in the presence of the series of catalysts under study. Reaction conditions: 1-octene ( $3 \mathrm{ml}$ ), n-heptane as solvent ( $3 \mathrm{ml})$, catalyst 10 mg, initial $\mathrm{H}_{2}$ pressure 30 bar, $120^{\circ} \mathrm{C}$, magnetic stirring in autoclave. 


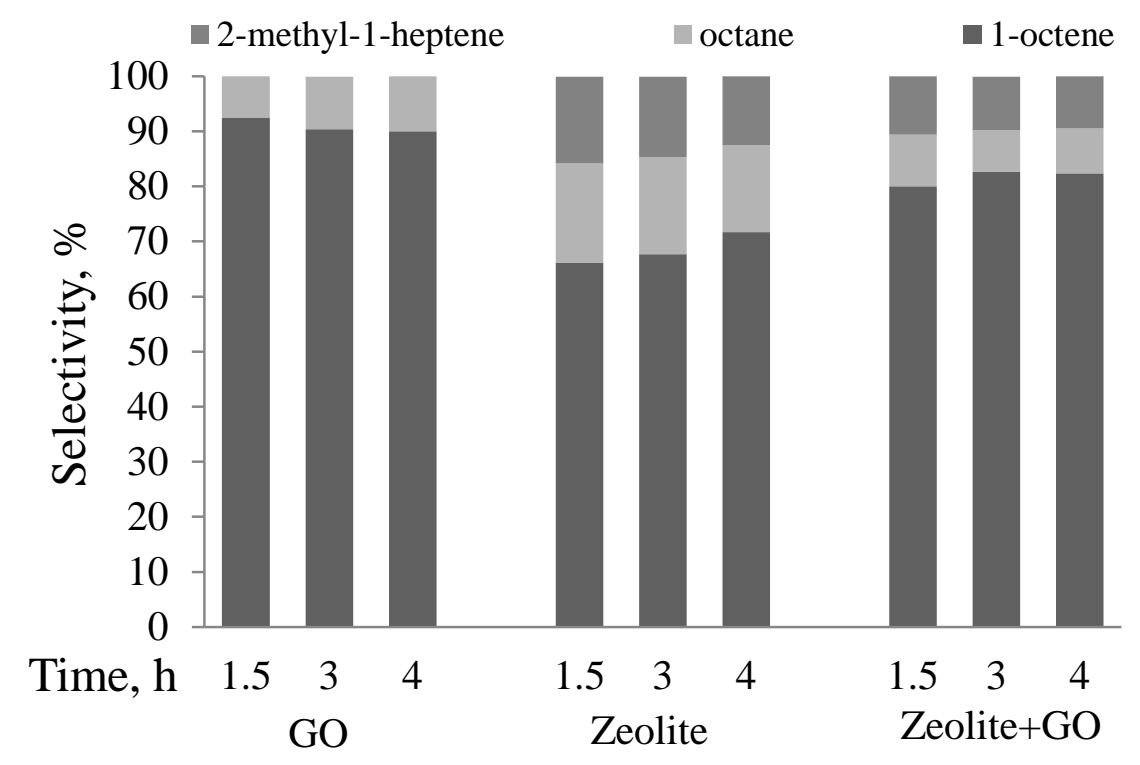

Figure 11. Variation of the conversion of 1-octene vs. time on RGO, Zeolite Beta and physical mixtures of two.

We also compared these catalysts with recently reported 3D graphene-like microporous carbons synthesized in a zeolite template $\mathrm{e}^{41}$ and with $0.5 \mathrm{wt} \% \mathrm{Pt}$ and Pd deposited onto the GO support. Compared to the 3D graphenes, plasma RGO catalysts showed an enhanced activity. Thus, after $4 \mathrm{~h}$ G2/60 afforded a conversion of cyclohexene higher than $90 \%$ compared to $64 \%$ for the $\beta$-3D graphene and 49\% for the Y-3D graphene. Both 0.5wt\% Pt and Pdwt\%/GO catalysts produced an almost complete reduction of cyclohexene but with the additional price of a $0.5 \mathrm{wt} \%$ noble metal loading.

Superior differences were also observed for the hydroisomeration and hydrogenation of 1octene. In this case, after 4 the conversion on G2/60 was of almost $60 \%$ compared to $41 \%$ for the $\beta$ $3 \mathrm{D}$ graphene and $26 \%$ for the Y-3D graphene. However, the selectivity to octane was superior on G2/60 that is an additional proof of the suppressing of the acidic functions during the $\mathrm{H}_{2}$-plasma treatment. $0.5 w t \% \mathrm{Pt}$ and Pdwt\%/GO provided very close selectivities to the two 3-D graphenes confirming thus the preservation of the acidic functions of the GO.

\section{Theoretical calculations.}

To provide some rationalization in support of the role of holes on the graphene sheet on their activity as hydrogenation catalysts, quantum chemical studies were performed. Theoretical calculations by using graphene sheet models of one or double carbon vacancies were applied to study the activation of $\mathrm{H}_{2}$ on the defective graphene surface. Prior to these calculations, preliminary calculations were carried out to establish the possible influence of the number of $\mathrm{C}$ atoms in the model 
on the geometry. Models of graphene sheets (from $8 \times 8$ up to $4 \times 4$ carbons were used) determine their geometry. All optimizations of defect-free graphenes afforded similar minimum structures and, for that reason, the simplest $4 \times 4$ graphene sheet model was chosen for further studies. This graphene sheet is characterised by $\mathrm{C}\left(\mathrm{sp}^{2}\right)-\mathrm{C}\left(\mathrm{sp}^{2}\right)$ bond lengths between 1.41 and $1.43 \AA$, being significantly shorter near to the graphene edge (ca. $1.38 \AA$ ).

Removal of one carbon atom (colored as red in Figure 8) generates a monovacancy that leads to a metastable graphene in where the carbon vacancy causes a restructuration of the sheet appearing a 5- and another 9- membered ring, in agreement also with previous DFT calculations. ${ }^{42}$ In order to characterize theoretically the model for a carbon vacancy, geometry optimization was performed using two different calculations. It was estimated that bond lengths and dihedral angles remained unchanged regardless the different PBE0/6-31G(d) or PBE0/6-31+G(d,p) basis sets used, thus, increasing the confidence on the calculations with regard to the geometry of the optimized model of monovacant graphene. The most notable outcome from these calculations is a large $\mathrm{C}\left(\mathrm{sp}^{3}\right)-\mathrm{C}\left(\mathrm{sp}^{3}\right)$ distance about $1.73 \AA$ calculated for the 5-membered ring appearing as consequence of the carbon vacancy and asymmetric bond length distribution around the hole of the vacancy displaying values in the range between 1.35 and $1.49 \AA$ (Figure 11).

a)

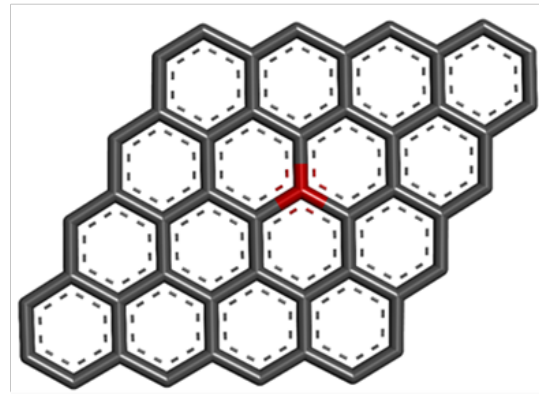

c)

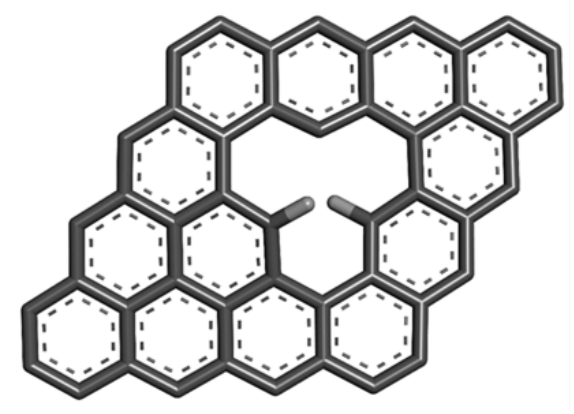

b)

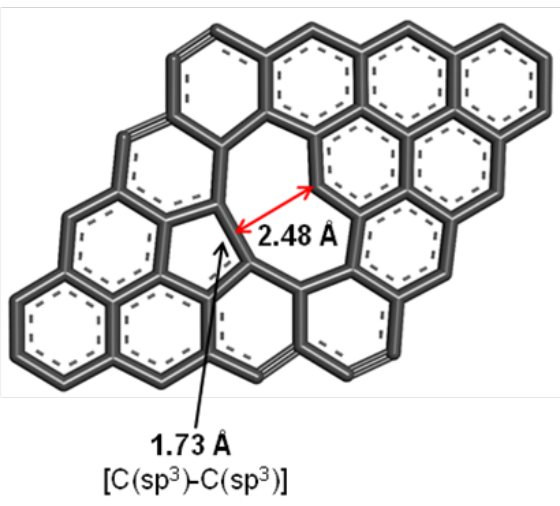

d) 
Figure 12. Generation of the carbon vacancy on the $4 \times 4$ graphene model by removal of the carbon atom indicated in red in part a. Then, the geometry of the resulting model was optimized at PBE0/6$31 \mathrm{G}(\mathrm{d})$ level of theory (b). Dissociative $\mathrm{H}_{2}$ adsorption at a monovancancy hole presented from two different perspectives (c and d) calculated at the same level of theory. Peripheral hydrogen atoms are omitted.

In order to achieve activation of $\mathrm{H}_{2}$ inside the cavity of the monovacant graphene sheet, the starting structure for the calculation was built by placing $\mathrm{H}_{2}$ molecule inside the vacancy. It was realized that the distance between the centroid of $\mathrm{C}\left(\mathrm{sp}^{3}\right)-\mathrm{C}\left(\mathrm{sp}^{3}\right)$ and the opposite edge of the vacancy (2.48 A, Figure 12) is sufficiently long to accommodate a $\mathrm{H}_{2}$ molecule having a bond length of 0.74 $\AA$ [at PBE0/6-31G(d) level of theory] and an estimated total length of $1.04 \AA$. Then, the system constituted by the model of a single carbon atom vacancy and a $\mathrm{H}_{2}$ molecule was allowed to relax to the minimum energy.

After the optimization process, the outcome showed a stable $(-2.4 \mathrm{eV})$ dissociative absorption of $\mathrm{H}_{2}$ at the vacancy site, affording two new $\mathrm{C}-\mathrm{H}$ bonds as presented in models c and d of Figure 12. This estimation is in accordance with previous calculations for other different graphene models that also concluded the formation of C-H bonds. ${ }^{43}$ Indeed, the formation of these new C-H bonds provokes a symmetrical reconstruction of the vacancy hole in which all carbon around the edge own a $\mathrm{sp}^{2}$ character. On the other hand, the $\mathrm{H} \cdots \mathrm{H}$ bond distance becomes dramatically increased by the chemisorption from the $0.74 \AA$ length for isolated $\mathrm{H}_{2}$ molecule to $1.94 \AA$ when interacting with the graphene model with a single carbon atom vacancy, indicating the occurrence of $\mathrm{H}-\mathrm{H}$ bond dissociation. Planarity of the model is also disturbed by this $\mathrm{H}_{2}$ chemisorption, two new $\mathrm{C}-\mathrm{H}$ bonds appearing above and below the average graphene plane (Figure 12, drawing d).

A different situation emerged when double carbon vacancy on the $4 \times 4$ graphene model was considered (Figure 13). Similarly to the monovacancy model, optimization of the geometry in the divacancy models leads to a reconstruction around the defect resulting in the appearance of three new rings of 5, 8 and 5 members. The divacancy model continues being completely planar after geometry optimization, with similar average $\mathrm{C}\left(\mathrm{sp}^{2}\right)-\mathrm{C}\left(\mathrm{sp}^{2}\right)$ bond lengths (ca. $1.43 \AA$ ). However, a significant difference was the $\mathrm{C}\left(\mathrm{sp}^{3}\right)-\mathrm{C}\left(\mathrm{sp}^{3}\right)$ bond lengths that were 1.73 and $1.56 \AA$ for mono- and divacancy models, respectively. Moreover, an additional stabilization of $-0.3 \mathrm{eV}$ was achieved in the 
calculations of the graphene model for divacancy, when a triplet spin multiplicity rather than a singlet configuration was considered.
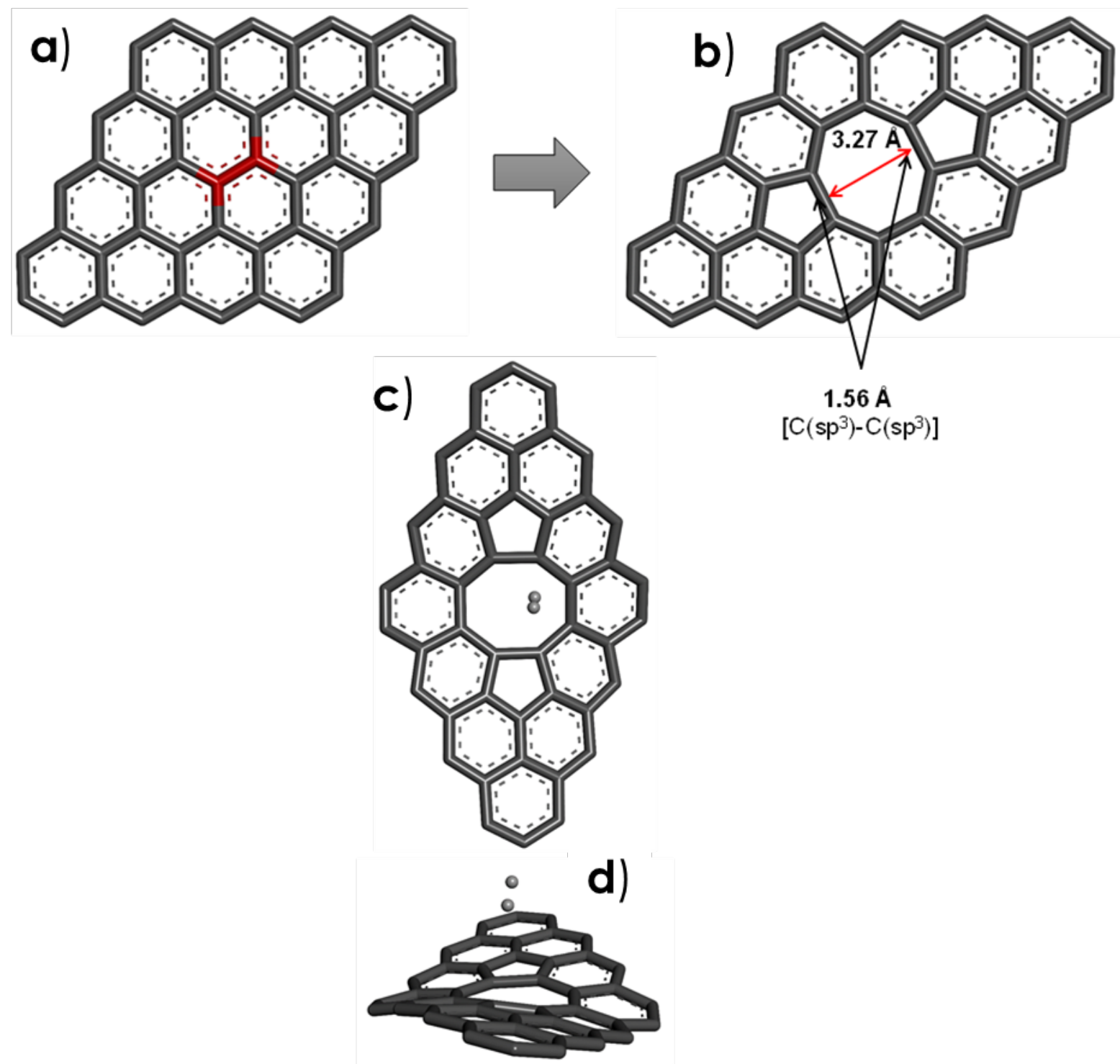

Figure 13. (a, b) Formation of two carbon vacancies in a $4 \times 4$ graphene model by removal of atoms indicated in red. The resulting model for divacant graphene was, then, optimized at PBE0/6-31G(d) level of theory. (c, d) Top and side views of $\mathrm{H}_{2}$ position upon optimization at the same level of theory. Pheripheral hydrogen atoms are omitted.

One important feature that arises from the geometry optimization for the double vacancy graphene sheet model is that the distance between the two opposite 5-membered rings edges was 3.27 $\AA$ (Figure 13), even larger than that of the graphene model for monovacancy. It is expected that the dimensions of the hole will play a large role in $\mathrm{H}_{2}$ activation, since the current state of the art on frustrated Lewis acid-base pairs is based on opposite sites at a short distance commensurate with the 
$\mathrm{H}_{2}$ bond length, but sufficiently long to avoid the collapse of the acid and base sites. ${ }^{44,45}$ Therefore, it appears that there is narrow distance range in which the $\mathrm{H}_{2}$ molecule can be activated. Similarly here, vacancies of adequate dimensions should be necessary to produce efficient $\mathrm{H}_{2}$ activation.

In view of these considerations, a $\mathrm{H}_{2}$ molecule was initially placed at the center inside the hole defined by the divacancy, parallel to the graphene plane, before starting the optimization of the system. Upon optimization, the results show a relocation of $\mathrm{H}_{2}$ molecule ending up aligned at the top of the vacancy hole (Figure 13 ) at an optimal distance $R_{\mathrm{H} 2} \cdots$ centroid of $3.10 \AA .{ }^{46}$ In this case, stabilization involves a weak binding energy of $-0.1 \mathrm{eV}\left(\Delta E_{\text {bind }}=-1.2 \mathrm{kcal} \mathrm{mol}^{-1}\right)$, such value being in the range expected for van der Waals interactions. Even though the $\mathrm{H}_{2}$ molecule was not bonded to graphene, the non-covalent contact caused a graphene plane distortion from $\phi=179.4^{\circ}$ to $1.1^{\circ}$. With regard to the $\mathrm{H}-\mathrm{H}$ bond length, $R_{\mathrm{H}-\mathrm{H}}$, after optimization of the system, it was calculated that it remains unchanged (0.74 $\AA$ ) respect the value corresponding to isolated $\mathrm{H}_{2}$ molecules. However, a significant polarization of this $\mathrm{H}_{2}$ bond as consequence of the interaction with the graphene sheet was the most notable outcome of the calculation. Thus, upon optimization at the PBE0/6-31G(d) level of theory a slight charge density $\mathrm{H}^{\delta+}-\mathrm{H}^{\delta-}$ (Mulliken charge: +0.07 and -0.012, respectively), as well as a dipole moment $(\mu=0.3 \mathrm{D}$ ) through the double vacancy hole were calculated, as consequence of the interaction with the surface of the divacant graphene model. Obviously, this bond polarization does not occur in gas-phase $\mathrm{H}_{2}$ molecules and should be considered as $\mathrm{H}_{2}$ preactivation.

Therefore, the outcome of the present calculations with models of graphene sheets with one or two carbon atom vacancies indicate that there is a considerable restructuring of the carbon atoms around the vacancies and that this rearrangement notably affects the interaction with $\mathrm{H}_{2}$. One carbon atom vacancy appears to interact too strongly with $\mathrm{H}_{2}$ as consequence of the better match between distances in the vacancy hole and the size of the $\mathrm{H}_{2}$ molecule, but this can result in the creation of $\mathrm{C}$ $\mathrm{H}$ bonds that will be undesirable from the catalytic point of view, if their formation were not reversible. Moreover, no spectroscopic evidence for the creation of these $\mathrm{C}-\mathrm{H}$ bonds has been obtained by DRIFT spectroscopy. However, although the interaction of double vacancy with $\mathrm{H}_{2}$ molecules is weaker due to its larger dimensions and no $\mathrm{H}_{2}$ bond length increase is predicted, adsorption on the divacancy would lead to polarization of the $\mathrm{H}$ atoms that can result in some $\mathrm{H}_{2}$ preactivation towards hydrogenation of $\mathrm{C}=\mathrm{C}$ bonds. However, the small adsorption energy and slight polarization appear to be still too weak to cause activation of $\mathrm{H}_{2}$ molecules. Therefore, it seems that the exact nature of the active sites for $\mathrm{H}_{2}$ activation still remains open and it could probably involve the presence of some heteroatom at the site.

\section{General assessment}


Previous studied combining DFT calculations and H/D isotopic exchange demonstrated that $\mathrm{H}_{2}$ activation can take place at carbon atom vacancies, the activation energy depending on the way in which $\mathrm{H}_{2}$ approaches the site and the steric encumbrance for the allocation of $\mathrm{C}-\mathrm{H}$ bonds. ${ }^{47}$ In the case of GO acidic properties were dominant and, on this basis, these materials can catalyze transfer hydrogenation reactions. ${ }^{48}$ For the catalysts prepared by the hydrogen plasma treated GO two kinds of active sites are generated, as also confirmed by XPS, DRIFTs, $\mathrm{H}_{2}$ chemisorption and TPD- $\mathrm{H}_{2}$. They correspond to a combination of network vacancies responsible for the hydrogenation reactions, and functionalities like $\mathrm{OH}$ and $\mathrm{COOH}$ produced via a disproportionation process, responsible for the acidic behavior. DFT calculations made in this study gave theoretical support to these characterization. On this basis the hydrogenation activity can be attributed to the network vacancies, while the isomerization to the generated acidic sites.

\section{Conclusions.}

Precedents in the literature have shown that hydrogen plasma treatment is a useful technique to produce carbon vacancies and holes on graphene sheets. The purpose of the present study was to show that the generation of these holes can increase and tune the catalytic activity of graphene as metal-free hydrogenation catalyst, a reaction of large importance from the synthetic and industrial point of view. The characterization data obtained in the present study agrees with the expected creation of defects and holes by plasma irradiation of graphene and, in accordance with our initial hypothesis, the resulting treated graphenes exhibit higher hydrogen adsorption capacity and higher hydrogenation activity. Notably the observation of some activity typical of bifunctional hydrogenation/acidic catalysts has been observed for the case of 1-octene hydrogenation by the appearence of skeletal isomer. Theoretical calculations with models of mono- and divacancies indicate a large difference in their interaction with $\mathrm{H}_{2}$, calculations with the two models still provide an unsatisfactory rationalization of the $\mathrm{H}_{2}$ activation observed in catalysis. Thus, it seems that the issue of the exact structure of the hydrogenation sites remains still open and could probably involve oxygen atoms. Overall, the present study illustrates the possibility to engineer active sites on graphene by available treatments, tuning their catalytic activity and the need to combine experimental data and theory to gain a deep understanding on the catalytic process.

Indeed, the hydrogen plasma treatment emerges as a very green procedure to modify graphenes. The energetics of this treatment is much favorable to plasma. In the investigated experiments the maximal consumption was of $2 \mathrm{~W}$. This consumption for the time of the experiments corresponds to $3.78{ }^{\circ} \mathrm{C}$ that is completely insignificant. Noteworthy, to produce some non-selective 
chemical changes in these graphenes in the way have been produced by plasma, temperatures higher than $500{ }^{\circ} \mathrm{C}$ are necessary.

\section{Acknowledgements}

Financial support by the Spanish Ministry of Economy and Competitiveness (Severo Ochoa, CTQ2015-69563-CO2-R1 and Grapas) is gratefully acknowledged. AP thanks the Ministry for a Ramón y Cajal research associate contract. AFG thank the Center of Supercomputing of Galicia (CESGA) for the computational facilities. MM acknowledges financial support from the PN 16470104 project. VIP kindly acknowledges UEFISCDI for financial support (project PN-IIIP4-ID-PCE-2016-0146, Nr. 121/2017).

\section{Supporting information.}

Scheme of the plasma reactor used for treating graphene; Plots correlating $\mathrm{H}_{2}$ adsorption data and XPS parameters; Thermoprogrammed desorption plots for $\mathrm{H}_{2}$ and $\mathrm{NH}_{3}$; XPS C-O/C=O ratio; TEM images, Summary of the binding energy and intensity of the main components.

\section{References}

1. Grondal, C.; Jeanty, M.; Enders, D.,Organocatalytic cascade reactions as a new tool in total synthesis, Nature Chemistry 2010, 2 (3), 167-178.

2. Stephan, D. W.; Erker, G.,Frustrated Lewis Pairs: Metal-free Hydrogen Activation and More, Angewandte Chemie-International Edition 2010, 49 (1), 46-76.

3. Thomas, A.; Fischer, A.; Goettmann, F.; Antonietti, M.; Muller, J. O.; Schlogl, R.; Carlsson, J. M.,Graphitic carbon nitride materials: variation of structure and morphology and their use as metal-free catalysts, Journal of Materials Chemistry 2008, 18 (41), 4893-4908.

4. Wang, Y.; Wang, X. C.; Antonietti, M.,Polymeric Graphitic Carbon Nitride as a Heterogeneous Organocatalyst: From Photochemistry to Multipurpose Catalysis to Sustainable Chemistry, Angewandte Chemie-International Edition 2012, 51 (1), 68-89.

5. Dai, L.; Xue, Y.; Qu, L.; Choi, H.-J.; Baek, J.-B.,Metal-Free Catalysts for Oxygen Reduction Reaction, Chemical Reviews 2015, 115 (11), 4823-4892.

6. Navalon, S.; Dhakshinamoorthy, A.; Alvaro, M.; Antonietti, M.; Garcia, H.,Active sites on graphenebased materials as metal-free catalysts, Chemical Society Reviews 2017, 46 (15), 4501-4529.

7. Navalon, S.; Dhakshinamoorthy, A.; Alvaro, M.; Garcia, H.,Carbocatalysis by Graphene-Based Materials, Chemical Reviews 2014, 114 (12), 6179-6212.

8. Zhang, J. T.; Qu, L. T.; Shi, G. Q.; Liu, J. Y.; Chen, J. F.; Dai, L. M.,N,P-Codoped Carbon Networks as Efficient Metal-free Bifunctional Catalysts for Oxygen Reduction and Hydrogen Evolution Reactions, Angewandte Chemie-International Edition 2016, 55 (6), 2230-2234.

9. Kong, X. K.; Sun, Z. Y.; Chen, M.; Chen, C. L.; Chen, Q. W.,Metal-free catalytic reduction of 4nitrophenol to 4-aminophenol by N-doped graphene, Energy \& Environmental Science 2013, 6 (11), 32603266. 
10. Hu, H. W.; Xin, J. H.; Hu, H.; Wang, X. W.,Structural and mechanistic understanding of an active and durable graphene carbocatalyst for reduction of 4-nitrophenol at room temperature, Nano Research 2015, 8 (12), 3992-4006.

11. Trandafir, M. M.; Florea, M.; Neatu, F.; Primo, A.; Parvulescu, V. I.; Garcia, H.,Graphene from Alginate Pyrolysis as a Metal-Free Catalyst for Hydrogenation of Nitro Compounds, Chemsuschem 2016, 9 (13), 1565-1569.

12. Primo, A.; Neatu, F.; Florea, M.; Parvulescu, V.; Garcia, H.,Graphenes in the absence of metals as carbocatalysts for selective acetylene hydrogenation and alkene hydrogenation, Nature Communications 2014, 5.

13. Primo, A.; Parvulescu, V.; Garcia, H.,Graphenes as Metal-Free Catalysts with Engineered Active Sites, Journal of Physical Chemistry Letters 2017, 8 (1), 264-278.

14. Son, S.; Holroyd, C.; Clough, J.; Horn, A.; Koehler, S. P. K.; Casiraghi, C.,Substrate dependence of graphene reactivity towards hydrogenation, Applied Physics Letters 2016, 109 (24).

15. Tang, C.; Zhang, Q.,Nanocarbon for Oxygen Reduction Electrocatalysis: Dopants, Edges, and Defects, Advanced Materials 2017, 29 (13), 1604103.

16. Tang, C.; Wang, H. F.; Chen, X.; Li, B. Q.; Hou, T. Z.; Zhang, B.; Zhang, Q.; Titirici, M. M.; Wei, F.,Topological Defects in Metal-Free Nanocarbon for Oxygen Electrocatalysis, Advanced Materials 2016, 28 (32), 6845-6851.

17. Jia, Y.; Zhang, L.; Du, A.; Gao, G.; Chen, J.; Yan, X.; Brown, C. L.; Yao, X., Defect graphene as a trifunctional catalyst for electrochemical reactions, Advanced materials 2016, 28 (43), 9532-9538.

18. Tao, L.; Wang, Q.; Dou, S.; Ma, Z.; Huo, J.; Wang, S.; Dai, L., Edge-rich and dopant-free graphene as a highly efficient metal-free electrocatalyst for the oxygen reduction reaction, Chemical Communications 2016, 52 (13), 2764-2767.

19. Harpale, A.; Chew, H. B.,Hydrogen-plasma patterning of multilayer graphene: Mechanisms and modeling, Carbon 2017, 117, 82-91.

20. Harpale, A.; Panesi, M.; Chew, H. B.,Plasma-graphene interaction and its effects on nanoscale patterning, Physical Review B 2016, 93 (3).

21. Felten, A.; McManus, D.; Rice, C.; Nittler, L.; Pireaux, J. J.; Casiraghi, C.,Insight into hydrogenation of graphene: Effect of hydrogen plasma chemistry, Applied Physics Letters 2014, 105 (18).

22. Davydova, A.; Despiau-Pujo, E.; Cunge, G.; Graves, D. B.,Etching mechanisms of graphene nanoribbons in downstream $\mathrm{H}-2$ plasmas: insights from molecular dynamics simulations, Journal of Physics D-Applied Physics 2015, 48 (19).

23. Davydova, A.; Despiau-Pujo, E.; Cunge, G.; Graves, D. B.,H+ion-induced damage and etching of multilayer graphene in $\mathrm{H}-2$ plasmas, Journal of Applied Physics 2017, 121 (13).

24. Delfour, L.; Davydova, A.; Despiau-Pujo, E.; Cunge, G.; Graves, D. B.; Magaud, L.,Cleaning graphene: A first quantum/classical molecular dynamics approach, Journal of Applied Physics 2016, 119 (12).

25. Despiau-Pujo, E.; Davydova, A.; Cunge, G.; Delfour, L.; Magaud, L.; Graves, D. B.,Elementary processes of $\mathrm{H}-2$ plasma-graphene interaction: A combined molecular dynamics and density functional theory study, Journal of Applied Physics 2013, 113 (11).

26. Despiau-Pujo, E.; Davydova, A.; Cunge, G.; Graves, D. B.,Hydrogen Plasmas Processing of Graphene Surfaces, Plasma Chemistry and Plasma Processing 2016, 36 (1), 213-229.

27. Nieman, R.; Das, A.; Aquino, A. J. A.; Amorim, R. G.; Machado, F. B. C.; Lischka, H.,Single and double carbon vacancies in pyrene as first models for graphene defects: A survey of the chemical reactivity toward hydrogen, Chemical Physics 2017, 482, 346-354.

28. Sastre, G.; Forneli, A.; Almasan, V.; Parvulescu, V. I.; Garcia, H.,Isotopic H/D exchange on graphenes. A combined experimental and theoretical study, Applied Catalysis A: General 2017, 547 (Supplement C), 52-59.

29. Hummers, W. S.; Offeman, R. E.,PREPARATION OF GRAPHITIC OXIDE, Journal of the American Chemical Society 1958, 80 (6), 1339-1339.

30. Gaussian 09, Revision D.01, Frisch, M. J.; Trucks, G. W.; Schlegel, H. B.; Scuseria, G. E.; Robb, M. A.; Cheeseman, J. R.; Scalmani, G.; Barone, V.; Mennucci, B.; Petersson, G. A.; Nakatsuji, H.; Caricato, M.; Li, X.; Hratchian, H. P.; Izmaylov, A. F.; Bloino, J.; Zheng, G.; Sonnenberg, J. L.; Hada, M.; Ehara, M.; Toyota, K.; Fukuda, R.; Hasegawa, J.; Ishida, M.; Nakajima, T.; Honda, Y.; Kitao, O.; Nakai, H.; Vreven, T.; Montgomery, 
J. A., Jr.; Peralta, J. E.; Ogliaro, F.; Bearpark, M.; Heyd, J. J.; Brothers, E.; Kudin, K. N.; Staroverov, V. N.; Kobayashi, R.; Normand, J.; Raghavachari, K.; Rendell, A.; Burant, J. C.; Iyengar, S. S.; Tomasi, J.; Cossi, M.; Rega, N.; Millam, J. M.; Klene, M.; Knox, J. E.; Cross, J. B.; Bakken, V.; Adamo, C.; Jaramillo, J.; Gomperts, R.; Stratmann, R. E.; Yazyev, O.; Austin, A. J.; Cammi, R.; Pomelli, C.; Ochterski, J. W.; Martin, R. L.; Morokuma, K.; Zakrzewski, V. G.; Voth, G. A.; Salvador, P.; Dannenberg, J. J.; Dapprich, S.; Daniels, A. D.; Farkas, Ö.; Foresman, J. B.; Ortiz, J. V.; Cioslowski, J.; Fox, D. J. Gaussian, Inc., Wallingford CT, 2009.

31. Skowron, S. T.; Lebedeva, I. V.; Popov, A. M.; Bichoutskaia, E., Chem. Soc. Rev. 2015, 44, 3143-3176.

32. Dubin, S.; Gilje, S.; Wang, K.; Tung, V. C.; Cha, K.; Hall, A. S.; Farrar, J.; Varshneya, R.; Yang, Y.; Kaner, R. B.,A one-step, solvothermal reduction method for producing reduced graphene oxide dispersions in organic solvents, ACS nano 2010, 4 (7), 3845-3852.

33. Lucchese, M. M.; Stavale, F.; Ferreira, E. H. M.; Vilani, C.; Moutinho, M. V. O.; Capaz, R. B.; Achete, C. A.; Jorio, A., Carbon 2010, 48 (5), 1592-1597.

34. Stankovich, S.; Dikin, D. A.; Piner, R. D.; Kohlhaas, K. A.; Kleinhammes, A.; Jia, Y.; Wu, Y.; Nguyen, S. T.; Ruoff, R. S., Carbon 2007, 45 (7), 1558-1565.

35. Su, C. L.; Acik, M.; Takai, K.; Lu, J.; Hao, S. J.; Zheng, Y.; Wu, P. P.; Bao, Q. L.; Enoki, T.; Chabal, Y. J.; Loh, K. P., Nature Communications 2012, 3.

36. Gholami, J.; Manteghian, M.; Badiei, A.; Ueda, H.; Javanbakht, M., Luminescence 2016, 31 (1), 229235.

37. Zhang, C.; Dabbs, D. M.; Liu, L. M.; Aksay, I. A.; Car, R.; Selloni, A., Journal of Physical Chemistry C 2015, 119 (32), 18167-18176.

38. Selvakumar, D.; Sivaram, H.; Alsalme, A.; Alghamdi, A.; Jayavel, R., Journal of Materials ScienceMaterials in Electronics 2016, 27 (6), 6232-6241.

39. Chu, H. Y.; Rosynek, M. P.; Lunsford, J. H.,S Journal of Catalysis 1998, 178 (1), 352-362.

40. Ebitani, K.; Konishi, J.; Hattori, H., Journal of Catalysis 1991, 130 (1), 257-267.

41. Sazama, P.; Pastvova, J.; Rizescu, C.; Tirsoaga, A.; Parvulescu, V. I.; Garcia, H.; Kobera, L.; Seidel, J.; Rathousky, J.; Klein, P., ACS Catalysis 2018.

42. Oubal, M.; Picaud, S.; Rayez, M. T.; Rayez, J. C.,Structure and reactivity of carbon multivacancies in graphene, Computational and Theoretical Chemistry 2012, 990, 159-166.

43. Gurel, H. H.; Ozcelik, V. O.; Ciraci, S.,Dissociative Adsorption of Molecules on Graphene and Silicene, Journal of Physical Chemistry C 2014, 118 (47), 27574-27582.

44. Chase, P. A.; Stephan, D. W.,Hydrogen and amine activation by a frustrated Lewis pair of a bulky nheterocyclic carbene and B(C6F5)(3), Angewandte Chemie-International Edition 2008, 47 (39), 7433-7437.

45. Cheng, G. J.; Zhang, X. H.; Chung, L. W.; Xu, L. P.; Wu, Y. D.,Computational Organic Chemistry: Bridging Theory and Experiment in Establishing the Mechanisms of Chemical Reactions, Journal of the American Chemical Society 2015, 137 (5), 1706-1725.

46. For this distance, the middle of 8-membered ring, in which was located a ghost atom, was considered the centroid of divacancy graphene model. .

47. Sastre, G.; Forneli, A.; Almasan, V.; Parvulescu, V. I.; Garcia, H.,Isotopic H/D exchange on graphenes. A combined experimental and theoretical study, Applied Catalysis A: General 2017, 547, 52-59.

48. Coman, S. M.; Podolean, I.; Tudorache, M.; Cojocaru, B.; Parvulescu, V. I.; Puche, M.; Garcia, $\mathrm{H}$.,Graphene oxide as a catalyst for the diastereoselective transfer hydrogenation in the synthesis of prostaglandin derivatives, Chemical Communications 2017, 53 (74), 10271-10274. 